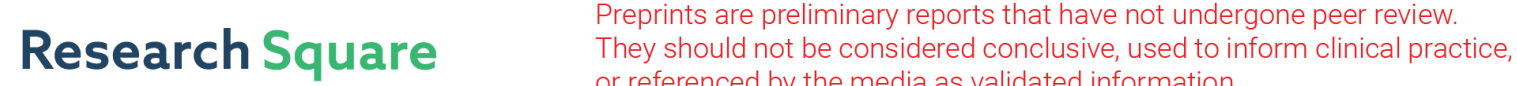 or referenced by the media as validated information. \\ Performance Enhancement in Multicore Fiber Using Trench Assisted Technique
}

\section{Salma Fatmia}

SRMIST: SRM Institute of Science and Technology

Manimegalai CT ( $\sim$ manimegc@srmist.edu.in )

SRM Institute of Science and Technology https://orcid.org/0000-0002-0356-5707

\section{Sabitha Gauni}

SRMIST: SRM Institute of Science and Technology

K. Kalimuthu

SRMIST: SRM Institute of Science and Technology

\section{Research Article}

Keywords: Trench Assisted technique, Multicore fiber, Coupled power theory, Coupled mode theory

Posted Date: April 13th, 2021

DOl: https://doi.org/10.21203/rs.3.rs-366348/v1

License: (c) (i) This work is licensed under a Creative Commons Attribution 4.0 International License. Read Full License 


\title{
Performance Enhancement in Multicore Fiber Using Trench Assisted Technique
}

\author{
Salma fathima T , C.T.Manimegalai, Sabitha Gauni,Kalimuthuk \\ Department of ECE \\ SRM institute of Science and Technology \\ Kattankulathur,Chennai-603203 \\ st3164@srmist.edu.in,manimegc@srmist.edu.in,sabithag@srmist.edu.in,kalimutk@srmist.edu.in
}

\begin{abstract}
Analysis of crosstalk in multicore fiber using trench assisted technique. To reduce the crosstalk between the cores in the fiber the coupled mode theory and coupled power theory are adopted for crosstalk estimation and considering different design parameters such as core pitch, bending radius and wavelength to optimize the crosstalk performance. The homogeneous fiber which works under single mode operation has been considered. The study of performance by varying the trench width is also analysed. Crosstalk variation in outer cores and center core of the fiber is studied. And the study of variation of crosstalk with 5 different core radius has been done. The numerical simulation results of crosstalk behavior over bending radius, wavelength and trench width is obtained.
\end{abstract}

Keywords-Trench Assisted technique, Multicore fiber, Coupled power theory, Coupled mode theory.

\section{Declarations}

\section{Funding- 'Not applicable'}

\section{Conflicts of interest/Competing interests}

The authors whose names are listed immediately below certify that they have NO affiliations with or involvement in any organization or entity with any financial interest (such as honoraria; educational grants; participation in speakers' bureaus; membership, employment, consultancies, stock ownership, or other equity interest; and expert testimony or patent-licensing arrangements), or non-financial interest (such as personal or professional relationships, affiliations, knowledge or beliefs) in the subject matter or materials discussed in this manuscript.

\section{Availability of data and material-'Not applicable'}

\section{INTRODUCTION}

In a single mode fiber with single core, the transmission capacity is restricted to nearly hundred Tbit/s. Then the introduction of Multi-core fiber came into existence to meet the current capacity crunch with multiple number of cores[1,2]. The increment in the number of cores provides it available to travel more modes, that enhances the transmission capacity, but alternatively creates interference of modes with one other. The availability of more number of core in a one cladding region can create sight of crosstalk between cores called intercore crosstalk (IC-XT). The intercore Crosstalk is analyzed using the two analytical approach called as coupled mode theory(CMT) and coupled power theory(CPT) [3]. The low interference is achieved by considering some modifications in the design parameters. Trench assisted technique is a method of deploying trench around the core which has lower refractive index than that of core and clad. The trench here is co-doped fluorine with silica[4]. Trench assisted technique is a better way to decrease the coupling between the adjacent cores in multi core fiber. As the trench around the core will reflect back the light signal into core avoiding the interference with the signal in adjacent core. The fiber with 9-cores is considered for the design with trench with $7 \mu \mathrm{m}$. To obtain crosstalk value less than value in contrast with the previously given intercore crosstalk value with trench width $4.5 \mu \mathrm{m}$ and $6 \mu \mathrm{m}[5,6]$. The study of Crosstalk impact on change in bending radius, core pitch,trench width, wavelength and different core sizes are obtained[14]. For reducing the electric field interference between the cores, several high-confinement of core designs and structures have been produced in Multicore fiber studies. Such as a small diameter and high-index small core structure is one of the option available. Air holes or Refractive index trench is other available method. Depressed cladding structure. Among them, the trench assisted core configuration have been mostly utilized for the Multicore fiber design, because of its better optical characteristics and fiber fabrication and splicing ease. The mismatch of phase between 
the cores can reduce or lower the crosstalk between the cores. Although, because of the flexibility and length of the optical fiber with multiple core in single cladding, we should take note of numerous longitudinal perturbations [7-10]. Particularly, the twists and bends of the Multicore fiber has huge effect on the propagation constants of the Multicore fiber cores [11-13]. The CMT and CPT has been applied to evaluate in terms of average crosstalk. The fiber works under single mode condition with homogeneous structure for the application of long-haul communication [14-16].

\section{PROPOSED DESIGN}

The fiber has 9-cores in the design with eight Cores in the outer ring arrangement and one core at the middle. By considering the long-haul communication the fiber is a homogeneous fiber which works under the single mode operation. Firstly the Core diameter and cladding diameter are opted as $9 \mu \mathrm{m}$ and $125 \mu \mathrm{m}$. With $4.5 \mu \mathrm{m}$ as core radius. After which the study is done with different core sizes varying from $6 \mu \mathrm{m}$ to $10 \mu \mathrm{m}$. The core refractive index, Cladding refractive index, and Trench refractive index of trench assisted fiber is denoted as $\mathrm{n}_{0}, \mathrm{n}_{1}$ and $\mathrm{n}_{2}$. Whereas the core-clad relative refractive index and clad-trench relative refractive index are denoted as $\Delta_{1}$ and $\Delta_{2}$, a is core radius and $\mathrm{a}_{2}$ is separation from core center to trench inner edge and a is the separation from core center to trench outer edge. ' $\Lambda$ ' is the Core pitch which is the distance between two adjacent Cores. For purpose of study of interference or crosstalk between Cores, the fiber length is assumed to be hundred kilometer (L) and 1550nm as propagation wavelength $(\lambda)$. Trench Width $\left(\mathrm{W}_{\mathrm{t}}\right)$ is considered equal to radius of the core at first and then compared with increasing the trench width to $7 \mu \mathrm{m}$. $d_{1}$ is the separation between middle core to any core at the outer ring arrangement and $d_{2}$ is separation between any two neighboring cores in outer ring.

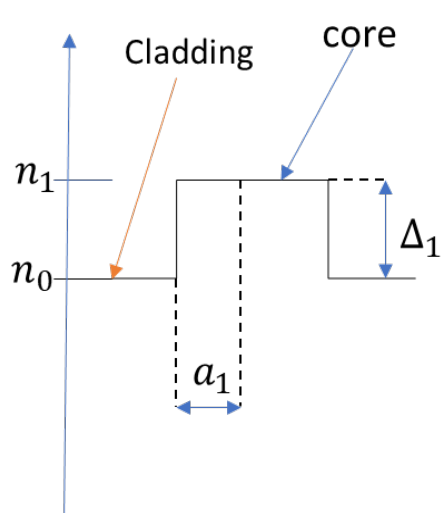

Figure 1: Step-index refractive index profile.

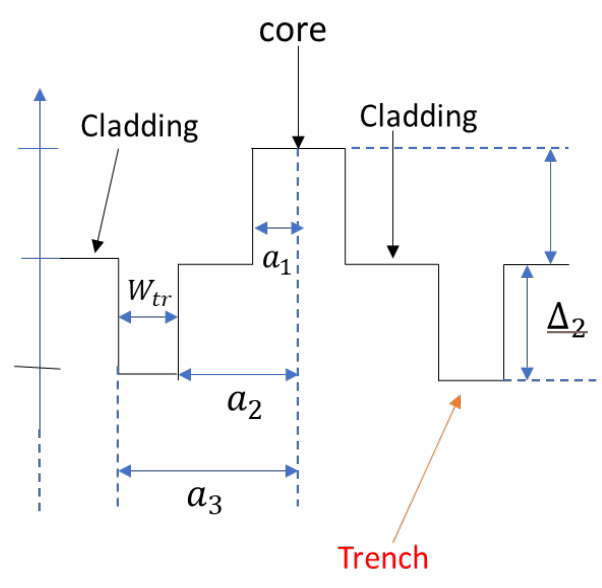

Figure 2: Trench assisted refractive index profile.

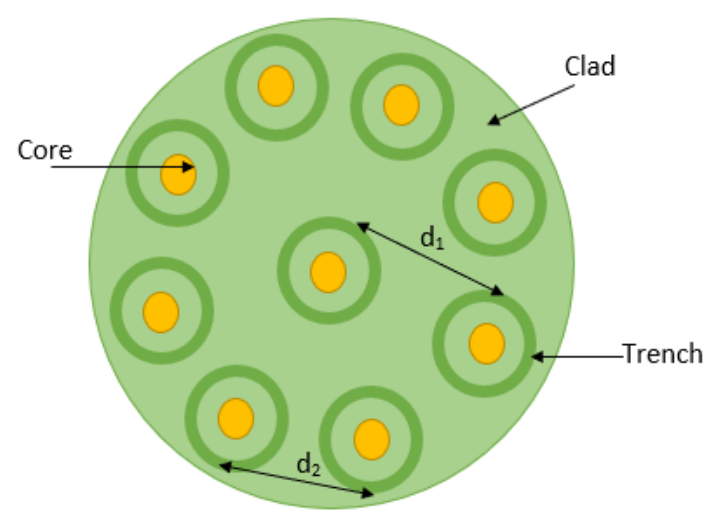

Figure 3: Cross-section view of MCF with 9-cores 


\section{ANALYSIS OF CROSSTALK}

Crosstalk between two nearby cores in multicore fiber is a major issue because of the incorporation of many cores in single cladding of the Fiber. Crosstalk between two adjacent core is given in terms optical signal power, as optical power passing through one of the core is coupled or interfered with power in adjacent core at the time of transmission. IC-XT between neighboring cores is given as[1][2],

$$
X T(d B)=10 \log \left(\frac{P^{\prime}}{P}\right)
$$

Here $P^{\prime} \& P$ are optical power outputs from input core $q$ and adjacent core $p$. We have to consider various longitudinal perturbations due to flexibility and the length of the fiber. In the multicore fiber especially the twists and bends have large impact propagation constants of the core. The CMT and CPT have been applied to evaluate the average Crosstalk[2][10].

To estimate Crosstalk of a step index structure, the calculation of mode Coupling Coefficient has been done,

$$
k_{p_{q}}^{\prime}=\frac{\sqrt{\Delta_{1}}}{a_{1}} \cdot \frac{U_{1}^{2}}{V_{1}^{3} k_{1}^{2} W_{1}} \cdot \sqrt{\frac{\Pi a_{1}}{W_{1} \Lambda}} \cdot \exp \left(-\frac{W_{1}}{a_{1}} \Lambda\right)
$$

Where, $\quad U_{1}=a_{1}\left(k^{2} n_{1}^{2}-\beta^{2}\right)^{1 / 2}$

$$
\begin{array}{cl}
W_{1}=a_{1}\left(\beta^{2}-k^{2} n_{0}^{2}\right)^{1 / 2} & V_{1}=2 \pi a_{1} n_{1}\left(2\left|\Delta_{1}\right|\right)^{1 / 2} / \lambda \\
\beta=\mathrm{k} x \text { neff } & \mathrm{k}=2 \Pi / \lambda
\end{array}
$$

$-\mathrm{V}$ number decides the modes propagating in the fiber.

$-\beta$ is called propagation constant.

$-\mathrm{K}$ denotes wave number.

-Wavelength of light in vaccum is denoted as ' $\lambda$ '.

$-K_{1}\left(W_{1}\right) \&\left(W_{2}\right)$ modified bessel function of 2 nd kind with 1 st order and $2^{\text {nd }}$ order.

- ‘ $\Lambda$ ' separation between two core i,e Core pitch.

For trench assisted fiber it can be evaluated similarly. The size of the $1^{\text {st }}$ cladding and trench not much larger, Coupling-coefficient of mode can be determined by the following approach,

$$
k_{p q}^{\prime \prime}=\frac{\sqrt{\Gamma} \sqrt{\Delta} 1}{a_{1}} \frac{U_{1}^{2}}{V_{1}^{3} k_{1}^{2} W_{1}} \sqrt{\frac{\pi a_{1}}{W_{1} \Lambda}} \exp \left(-\frac{w_{1} \wedge+2\left(w_{2}-w_{1}\right) w_{t)}}{a_{1}}\right)
$$

Where, $V_{2}=\frac{2 \pi a_{1} n_{0}\left(2\left|\Delta_{2}\right|\right)^{1 / 2}}{\lambda} \quad W_{2}=\left(V_{2}^{2}+W_{1}^{2}\right)^{1 / 2} \quad \Gamma=\frac{W_{1}}{W_{1}+\left[\left(W_{2}-W_{1}\right) \frac{W_{t}}{\Lambda}\right]}$

Now that we have an approach to estimate the MCC (Mode Coupling Co-efficient) between two neighboring Cores. The expression or formula for mean crosstalk between the cores can be estimated by,

$$
X T_{\mu}=\frac{2 k_{p q}^{2} R_{b}}{\beta \Lambda} \cdot L
$$

$X T \mu$ is the average crosstalk. $k_{p q}$ is the coupling coefficient. $R_{b}$ is the bending radius. $\Lambda$ is core pitch. $\mathrm{L}$ is the fiber length. 


\begin{tabular}{|l|c|c|}
\hline PARAMETER & VALUE & UNIT \\
\hline Core radius $\left(a_{1}\right)$ & $4.5[$ later 3 to $5 \mu \mathrm{m}]$ & $\mu \mathrm{m}$ \\
\hline Clad Diameter $(\mathrm{CD})$ & 125 & $\mu \mathrm{m}$ \\
\hline Core Refractive index $\left(n_{1}\right)$ & 1.4551 & - \\
\hline Clad refractive index $\left(n_{0}\right)$ & 1.45 & - \\
\hline Trench refractive index $\left(n_{2}\right)$ & 1.43743 & - \\
\hline Relative refractive index of core-clad $\left(\Delta_{1}\right)$ & 0.35 & $\%$ \\
\hline Relative refractive index of clad-trench $\left(\Delta_{2}\right)$ & $-0.35,-0.70,-1.40$ & $\mathrm{Km}$ \\
\hline Fiber length $(\mathrm{L})$ & 100 & $\mathrm{Nm}$ \\
\hline Wavelength $(\lambda)$ & 1550 & $\mu \mathrm{m}$ \\
\hline Pitch $(\Lambda)$ & 40 & $\mu \mathrm{m}$ \\
\hline Trench width $\left(w_{t}\right)$ & $4.5,7$ & \\
\hline
\end{tabular}

\section{SIMULATION RESULTS}

Considering the design parameters, the numerical simulation has been carried out using the MATLAB software. The crosstalk variation has been analyzed for different value of fiber bending radius and different for different wavelengths has been studied for trench width $4.5 \mu \mathrm{m}$ and compared for fiber with trench of $7 \mu \mathrm{m}$. The figure 4 and figure 5 gives the variation of crosstalk to change in bending radius at outer cores and inner core with trench width $4.5 \mu \mathrm{m}$. The figure 6 and 7 shows the variation of crosstalk to change in wavelength with trench width $4.5 \mu \mathrm{m}$. The figure 8 and 9 gives the variation of crosstalk to change in bending radius at outer cores and center core with trench width $7 \mu \mathrm{m}$. Similarly, the figure 10 and 11 shows the comparison of variation in crosstalk to change in bending radius with trench width $7 \mu \mathrm{m}$.

\section{A. simulation of crosstalk versus bending radius}

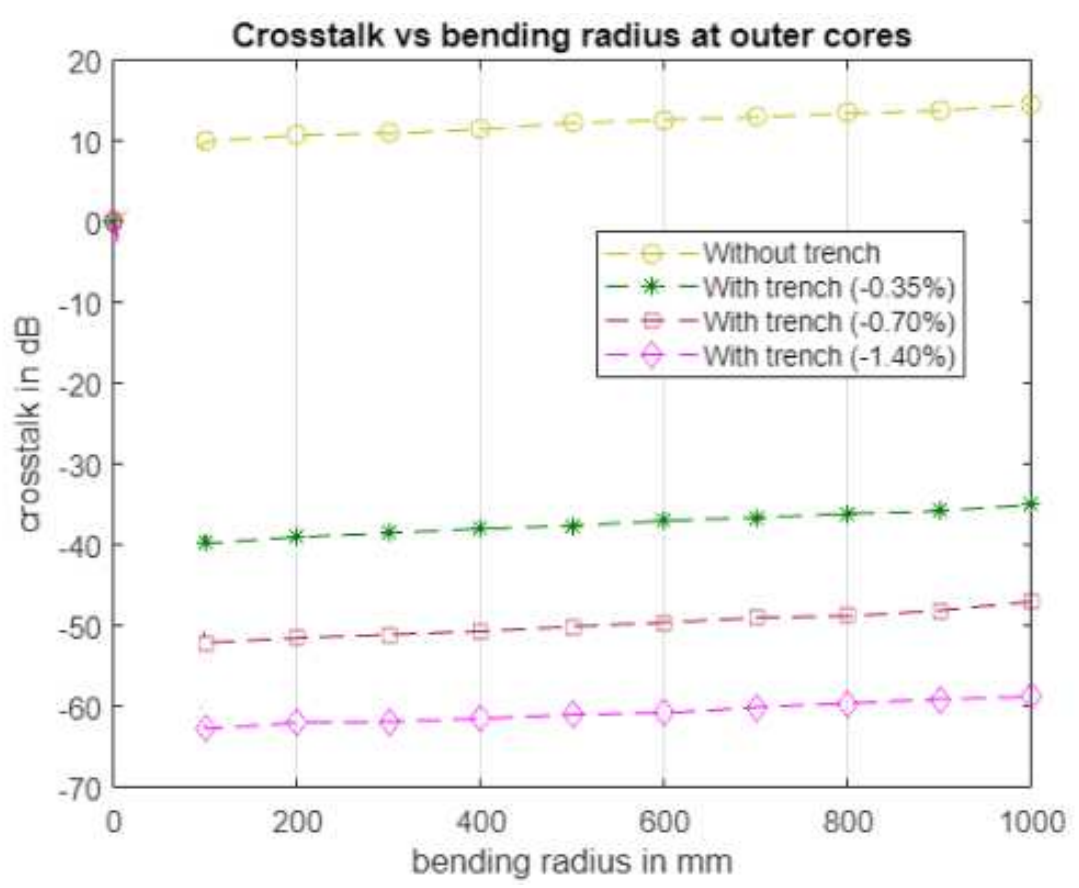


Figure 4: The relation between crosstalk and bending radius at outer cores.

The variation of crosstalk over different trench values has been noted. With the increase in bending radius the XT increases however the simulated results for fiber with trench width $4.5 \mu \mathrm{m}$ shows the behaviour of fiber with variation in bending radius. The crosstalk varies for without trench from 10 to $17 \mathrm{~dB}$, for trench with $\Delta_{2}=-0.35 \%$ the crosstalk varies from -39 to $-34 \mathrm{~dB}$, for trench with $\Delta_{2}=-0.70 \%$, crosstalk varies from -52 to $-48 \mathrm{~dB}$ and for trench with $\Delta_{2}=-1.40 \%$ crosstalk varies -62 to $-58 \mathrm{~dB}$.

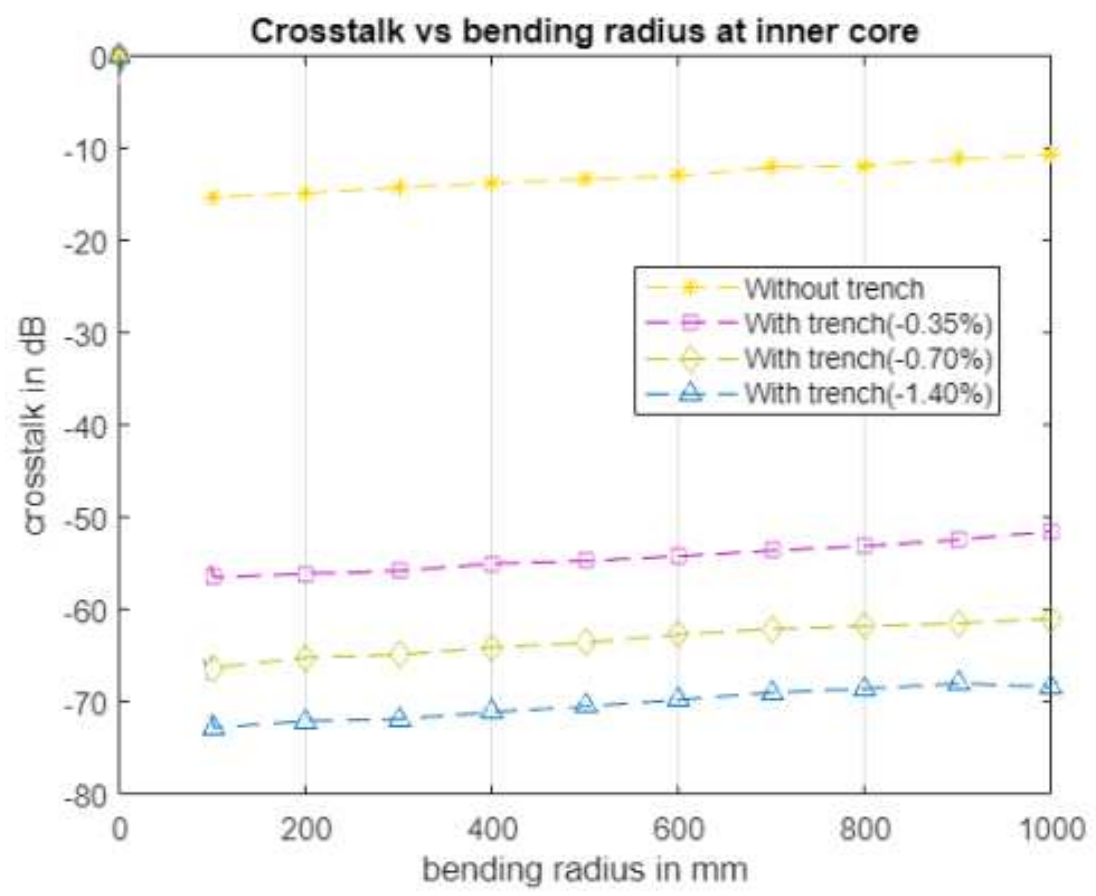

Figure 5: The relation between crosstalk and bending radius at inner core.

The variation of crosstalk over different trench values has been noted. With the increase in bending radius the XT increases however the simulated results for fiber with trench width $4.5 \mu \mathrm{m}$ shows the behaviour of fiber with variation in bending radius. The crosstalk varies for without trench from -15 to $-10 \mathrm{~dB}$, for trench with $\Delta_{2}-0.35 \%$ the crosstalk varies from -56 to $-51 \mathrm{~dB}$, for trench with $\Delta_{2}=-0.70 \%$, crosstalk varies from -65 to $-61 \mathrm{~dB}$ and for trench with $\Delta_{2}=-1.40 \%$ crosstalk varies -72 to $-66 \mathrm{~dB}$.

C. crosstalk versus wavelength at outer core 


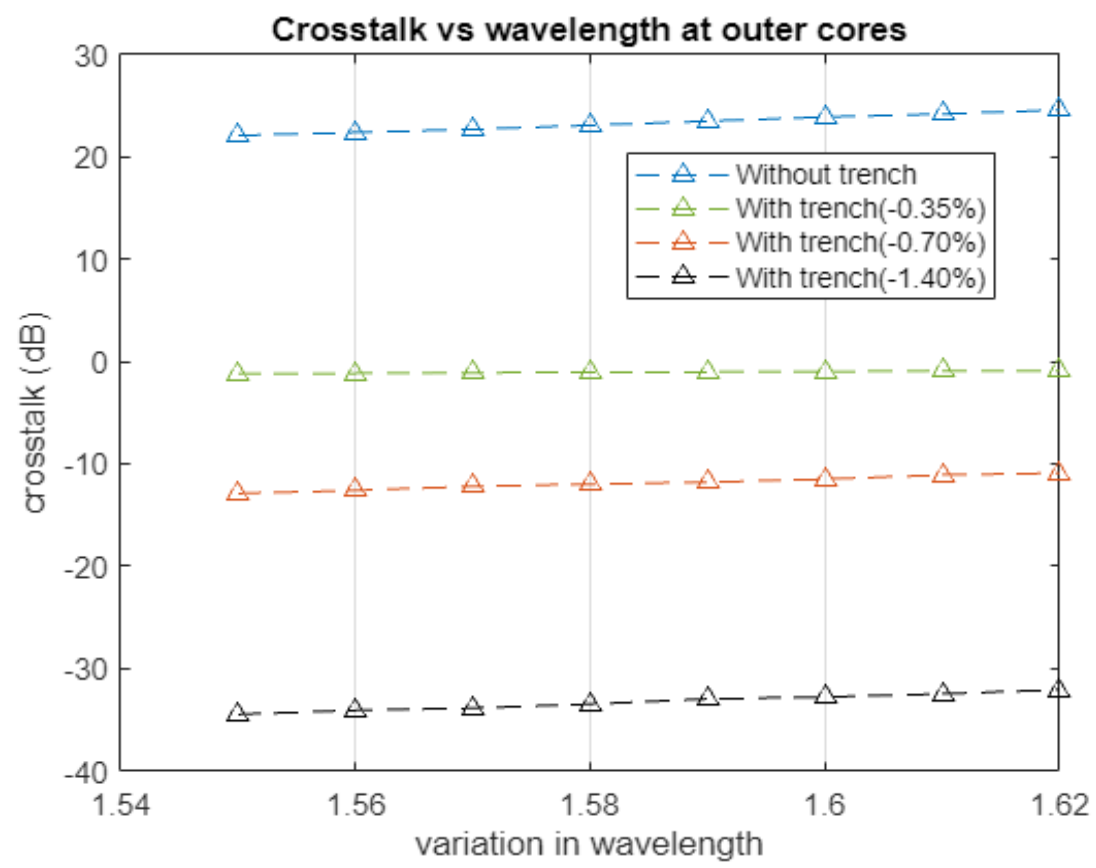

Figure 6: The relation between wavelength in $\mu \mathrm{m}$ and crosstalk in cores at outer ring of the fiber.

The variation of crosstalk over different trench values has been noted. With the increase in wavelength the XT increases, the simulated results for fiber with trench width $4.5 \mu \mathrm{m}$ shows the behaviour of fiber with variation in wavelength. The crosstalk varies for without trench from 21.74 to $25 \mathrm{~dB}$, for trench with $\Delta_{2}-0.35 \%$ the crosstalk varies from 1.19 to $-0.9 \mathrm{~dB}$, for trench with $\Delta_{2}=-0.70 \%$ crosstalk varies from -12 to $-10 \mathrm{~dB}$ and for trench with $\Delta_{2}=-1.40 \%$ crosstalk varies -34.07 to $-32 \mathrm{~dB}$.

\section{D. crosstalk versus wavelength at inner core}

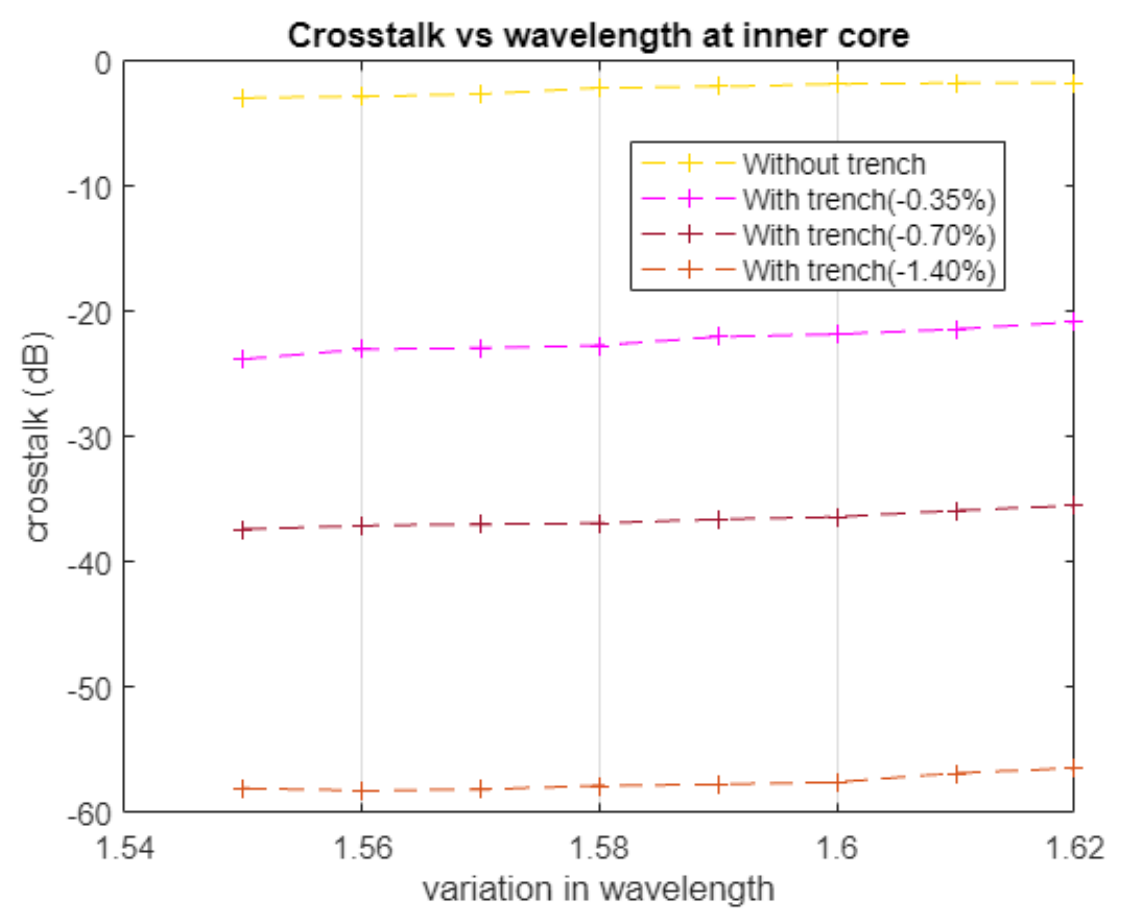

Figure 7: The relation between wavelength in $\mu \mathrm{m}$ and crosstalk at inner core, with core pitch.

The variation of crosstalk over different trench values has been noted. With the increase in wavelength the XT increases, the simulated results for fiber with trench width $4.5 \mu \mathrm{m}$ shows the behaviour of fiber with variation in wavelength. The crosstalk 
varies for without trench from 2.45 to $-1.9 \mathrm{~dB}$, for trench with $\Delta_{2}-0.35 \%$ the crosstalk varies from -22.8 to $-20 \mathrm{~dB}$, for trench with $\Delta_{2}=-0.70 \%$ crosstalk varies from -36.8 to $-34 \mathrm{~dB}$ and for trench with $\Delta_{2}=-1.40 \%$ crosstalk varies -58 to $-55 \mathrm{~dB}$.

E. Crosstalk versus bending radius at outer cores with trench width $7 \mu \mathrm{m}$

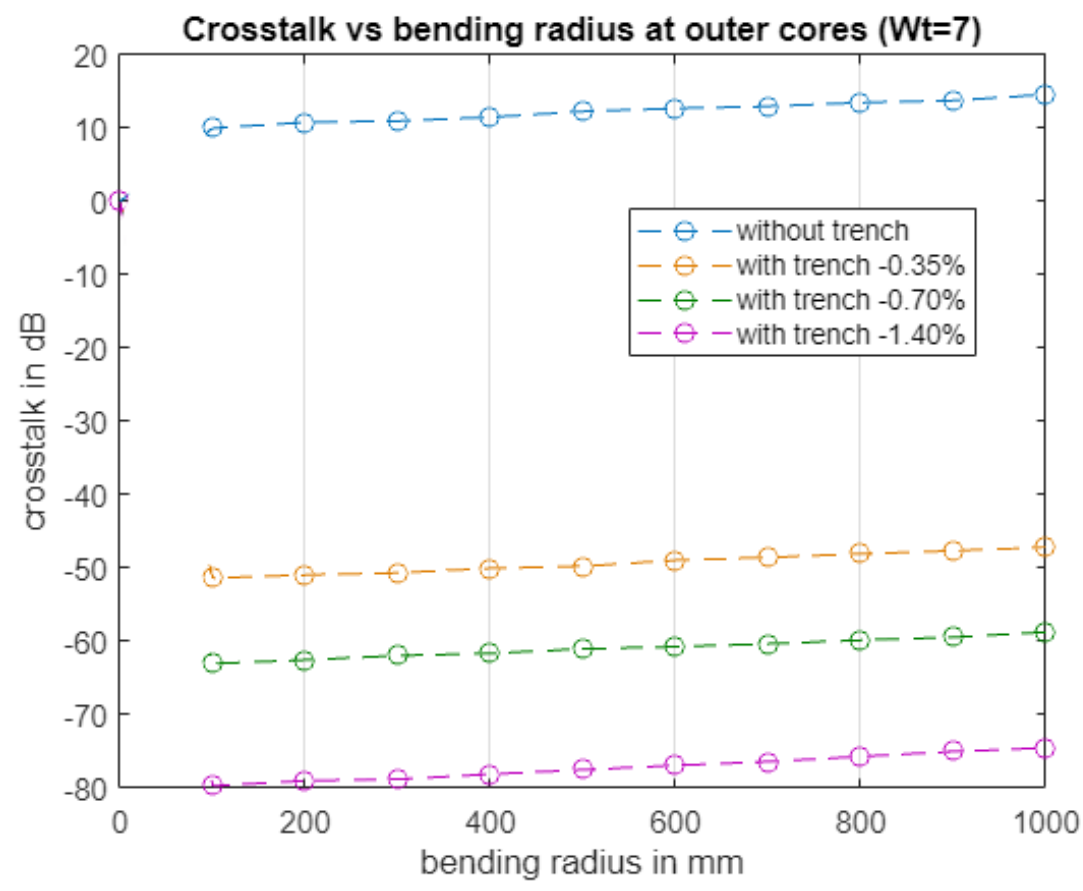

Figure 8: The relation between $\mathrm{XT}$ and bending radius at outer cores for $\mathrm{Wt}=7 \mu \mathrm{m}$.

The variation of crosstalk over different trench values has been noted. With the increase in bending radius the XT increases however the simulated results for fiber with trench width $7 \mu \mathrm{m}$ shows the behaviour of fiber with variation in bending radius. The crosstalk varies for without trench from 10 to $14 \mathrm{~dB}$, for trench with $\Delta_{2}-0.35 \%$ the crosstalk varies from -51.4 to $-46.9 \mathrm{~dB}$, for trench with $\Delta_{2}=-0.70 \%$, crosstalk varies from -63.1 to $-58.2 \mathrm{~dB}$ and for trench with $\Delta_{2}=-1.40 \%$ crosstalk varies -79.8 to 74.6dB.The crosstalk has been improved from $10 \mathrm{~dB}$ to $-79.8 \mathrm{~dB}$ at outer cores with trench width $7 \mu \mathrm{m}$.

F. Crosstalk versus bending radius at inner core with trench width $7 \mu \mathrm{m}$.

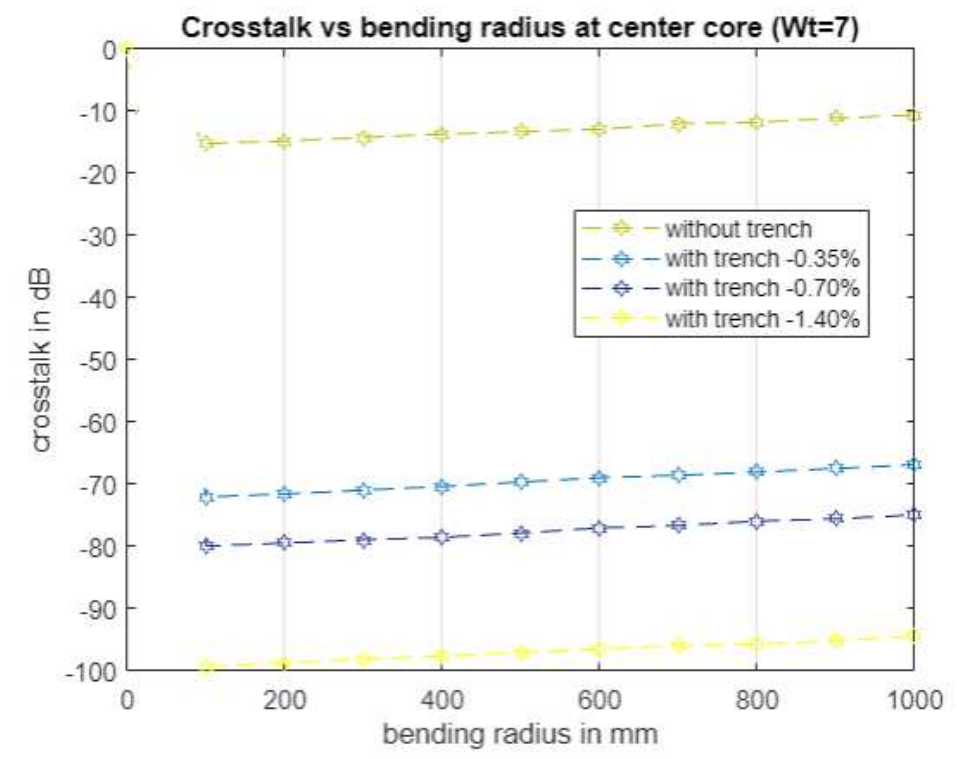

Figure 9: The relation between $\mathrm{XT}$ and bending radius at center core for $\mathrm{Wt}=7 \mu \mathrm{m}$. 
The variation of crosstalk over different trench values has been noted. With the increase in bending radius the XT increases however the simulated results for fiber with trench width $7 \mu \mathrm{m}$ shows the behaviour of fiber with variation in bending radius. The crosstalk varies for without trench from -15 to $-10 \mathrm{~dB}$, for trench with $\Delta_{2}-0.35 \%$ the crosstalk varies from -72.1 to $-66.9 \mathrm{~dB}$, for trench with $\Delta_{2}=-0.70 \%$, crosstalk varies from -80 to $-75 \mathrm{~dB}$ and for trench with $\Delta_{2}=-1.40 \%$ crosstalk varies -99.3 to 94.5dB.The crosstalk has been improved from $-15 \mathrm{~dB}$ to $-99.3 \mathrm{~dB}$ at center core with trench width $7 \mu \mathrm{m}$.

G. Comparison of Crosstalk vs bending radius at outer core with trench width 4.5 and $7 \mu m$.

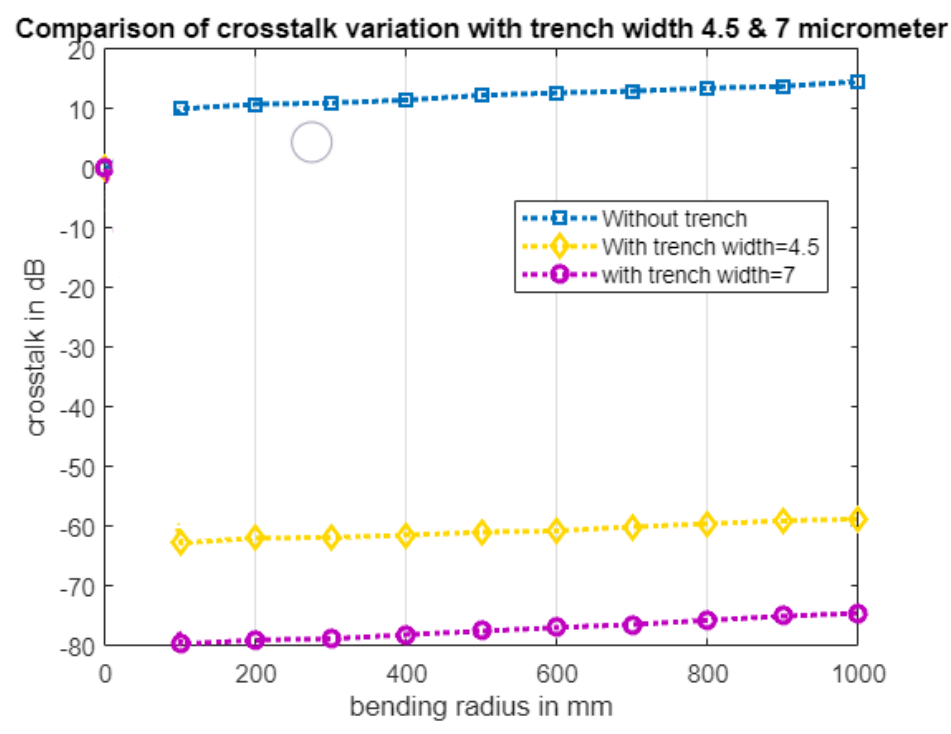

Figure 10: Shows the comparison of behavior of $\mathrm{XT}$ with variation in bending radius for $\mathrm{Wt}=4.5$ and $7 \mu \mathrm{m}$ at outer cores.

The graph shows the comparison of crosstalk in TA-MCF with two different trench width values such as $\mathrm{Wt}=4.5 \mu \mathrm{m}$ and $7 \mu \mathrm{m}$ at outer cores in the structure. Where the fiber with trench width $7 \mu \mathrm{m}$ shows the lower crosstalk performance compared to fiber with trench width $4.5 \mu \mathrm{m}$. The maximum of $-79.8 \mathrm{~dB}$ is achieved with $7 \mu \mathrm{m}$ whereas it is $-62 \mathrm{~dB}$ for $4.5 \mu \mathrm{m}$ at outer cores.

H. Comparison of Crosstalk versus bending radius at center core with trench width 4.5 and $7 \mu \mathrm{m}$

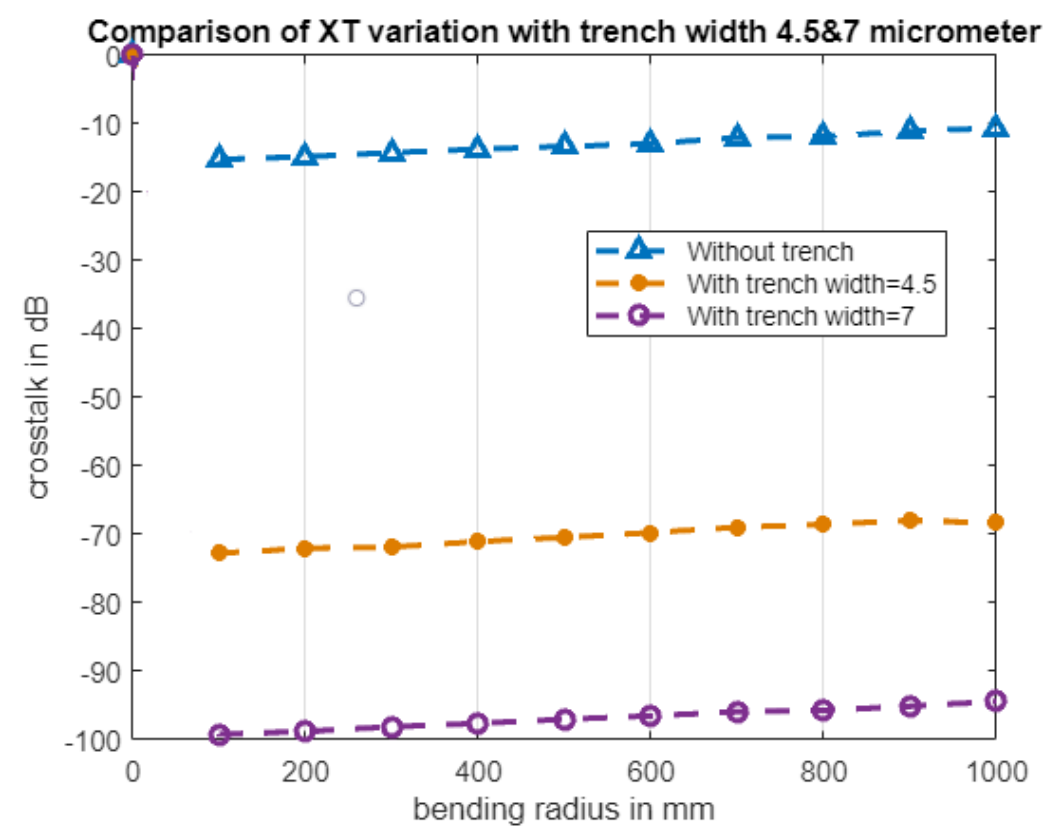

Figure 11: Shows the comparison of behavior of XT with variation in bending radius for $\mathrm{Wt}=4.5$ and $7 \mu \mathrm{m}$ at inner core. 
The graph shows the comparison of crosstalk in TA-MCF with two different trench width values such as $\mathrm{Wt}=4.5 \mu \mathrm{m}$ and $7 \mu \mathrm{m}$ at inner core in the structure. Where the fiber with trench width $7 \mu \mathrm{m}$ shows the lower crosstalk performance compared to fiber with trench width $4.5 \mu \mathrm{m}$. The maximum of $-99.3 \mathrm{~dB}$ is achieved with $7 \mu \mathrm{m}$ whereas it is $-72 \mathrm{~dB}$ for $4.5 \mu \mathrm{m}$ at center core.

The different core sizes has been considered namely C1,C2,C3,C5 and C5. To study the performance of crosstalk by considering different core radius and find the best core size for trench assisted technique. Therefore $\mathrm{C} 1=5 \mu \mathrm{m}, \mathrm{C} 2=4.5 \mu \mathrm{m}, \mathrm{C} 3=4 \mu \mathrm{m}$, $\mathrm{C} 4=3.5 \mu \mathrm{m}$ and $\mathrm{C} 5=3 \mu \mathrm{m}$. And the study has been done with respect to bending radius, wavelength and trench width.

\section{I.simulation of crosstalk versus bending radius for different core sizes at $-0.70 \%$ trench depth}

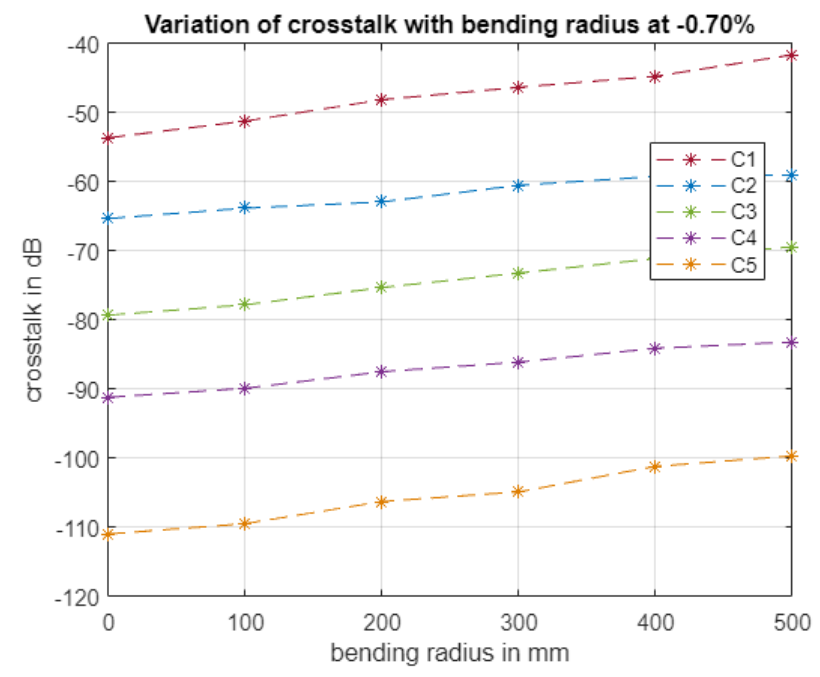

Fig 13: The crosstalk increases with increase in bending radius at trench depth $-0.70 \%$.

The above graph shows the comparison of crosstalk of different core sizes with bending radius at $-0.70 \%$ relative refractive index for $\mathrm{C} 1, \mathrm{C} 2, \mathrm{C} 3, \mathrm{C} 4$ and $\mathrm{C} 5$. The maximum of $-53 \mathrm{~dB}$ for $\mathrm{C} 1$ and minimum of $-110 \mathrm{~dB}$ for $\mathrm{C} 5$ has been obtained.

J.simulation of crosstalk versus bending radius for different core sizes at $-1.40 \%$ trench depth

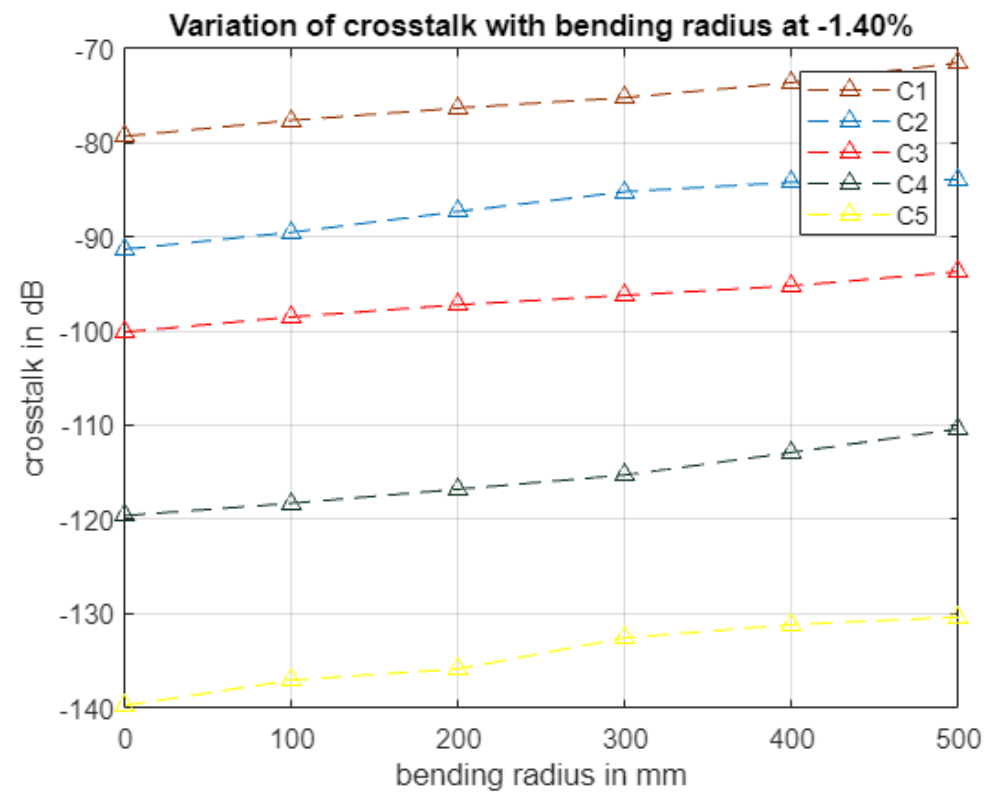

Fig 14: The crosstalk increases with increase in bending radius at trench depth $-1.40 \%$. 
The above graph shows the comparison of crosstalk of different core sizes with bending radius at $-1.40 \%$ relative refractive index for $\mathrm{C} 1, \mathrm{C} 2, \mathrm{C} 3, \mathrm{C} 4$ and $\mathrm{C} 5$. The maximum of $-79 \mathrm{~dB}$ for $\mathrm{C} 1$ and minimum of $-140 \mathrm{~dB}$ for $\mathrm{C} 5$ has been obtained.

K.simulation of crosstalk versus wavelength for different core sizes at $-0.70 \%$ trench depth

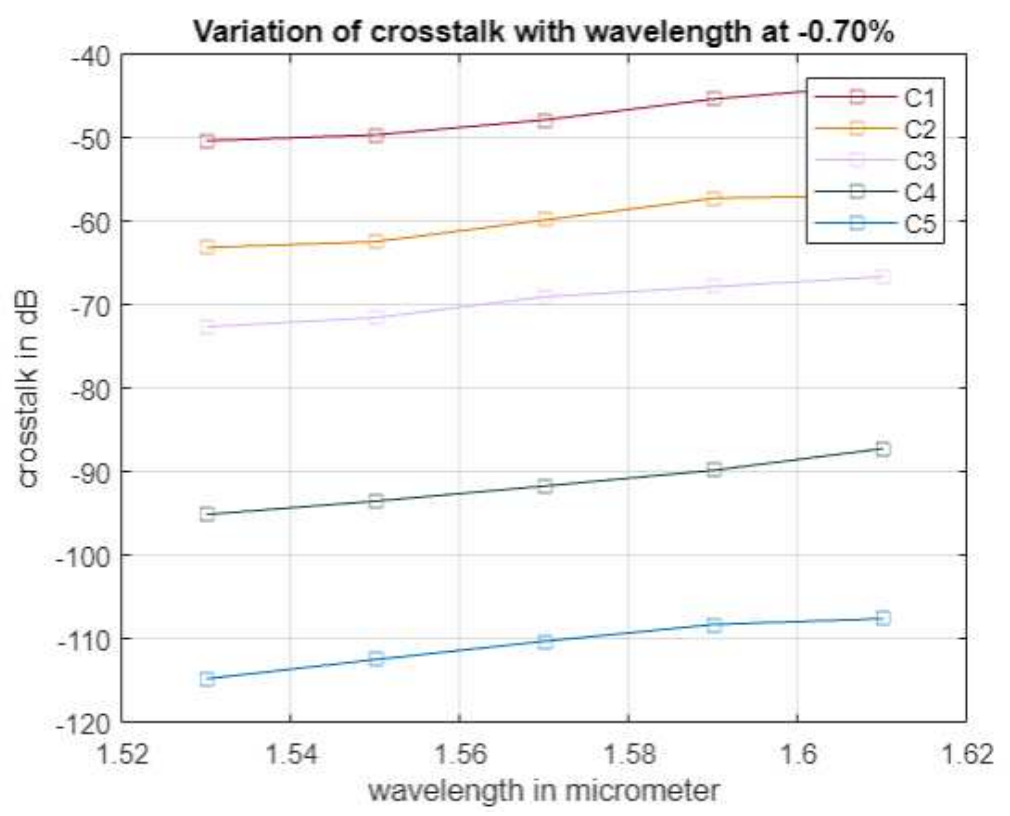

Fig 15: The crosstalk increases with increase in wavelength at trench depth $-0.70 \%$.

The above graph shows the comparison of crosstalk of different core sizes with wavelength at $-0.70 \%$ relative refractive index for $\mathrm{C} 1, \mathrm{C} 2, \mathrm{C} 3, \mathrm{C} 4$ and $\mathrm{C} 5$. The maximum of $-50 \mathrm{~dB}$ for $\mathrm{C} 1$ and minimum of $-115 \mathrm{~dB}$ for $\mathrm{C} 5$ has been obtained.

L.simulation of crosstalk versus wavelength for different core sizes at $-1.40 \%$ trench depth

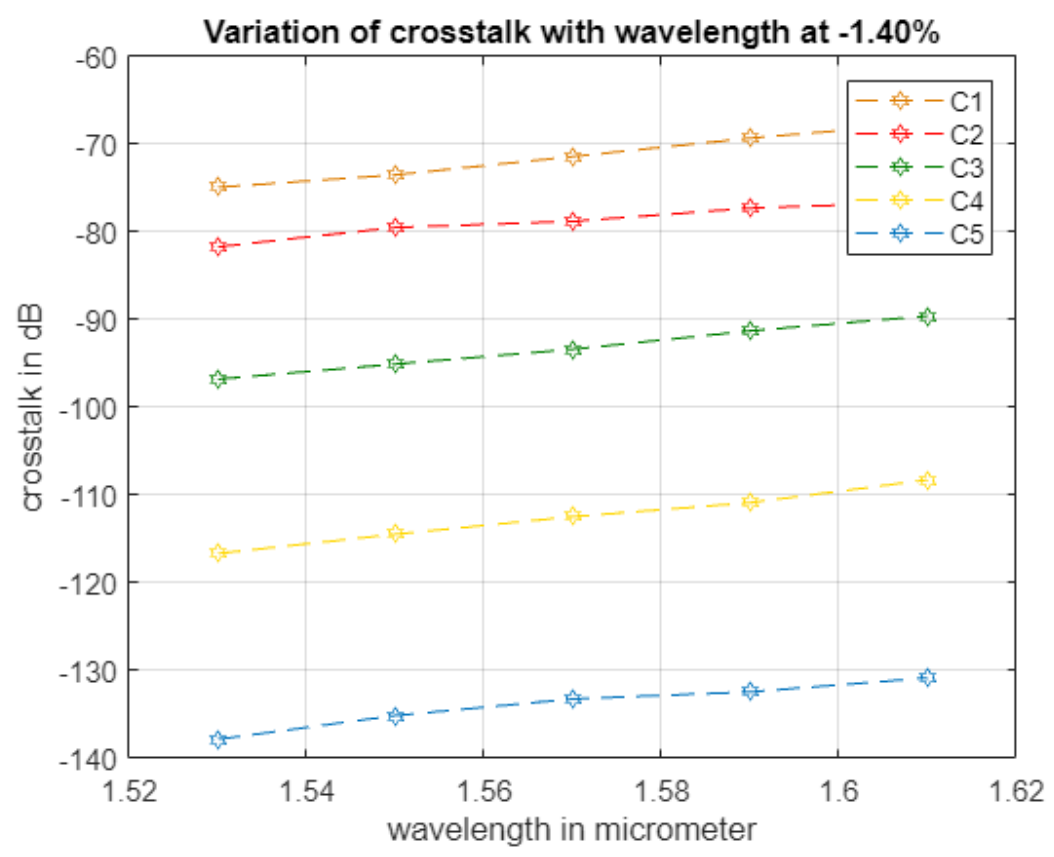

Fig 16: The crosstalk increases with increase in wavelength at trench depth $-1.40 \%$ 
The above graph shows the comparison of crosstalk of different core sizes with wavelength at $-1.40 \%$ relative refractive index for $\mathrm{C} 1, \mathrm{C} 2, \mathrm{C} 3, \mathrm{C} 4$ and $\mathrm{C} 5$. The maximum of $-75 \mathrm{~dB}$ for $\mathrm{C} 1$ and minimum of $-138 \mathrm{~dB}$ for $\mathrm{C} 5$ has been obtained.

\section{Simulation of crosstalk with respect to trench width}

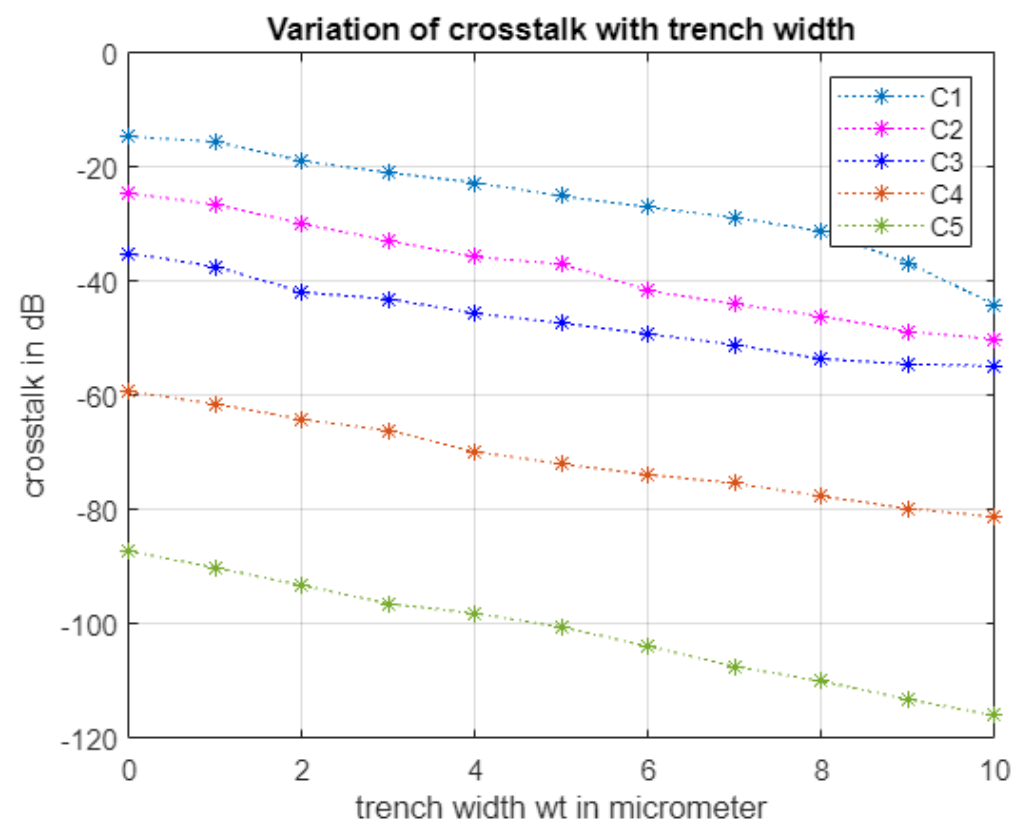

Fig 17: With the increase in trench width the crosstalk decreases

The above graph shows the comparison of crosstalk of different core sizes with trench width for C1, C2, C3, C4 and C5. The maximum of $-14 \mathrm{~dB}$ for $\mathrm{C} 1$ and minimum of $-85 \mathrm{~dB}$ for $\mathrm{C} 5$ has been obtained

\section{COMPARISON OF RESULTS}

\begin{tabular}{|c|c|c|c|c|c|}
\hline PARAMETERS & C1 $(5 \mu \mathrm{m})$ & $\mathrm{C2}(4.5 \mu \mathrm{m})$ & $\mathrm{C3}(4 \mu \mathrm{m})$ & $\mathrm{C} 4(3.5 \mu \mathrm{m})$ & $\mathrm{C5}(3 \mu \mathrm{m})$ \\
\hline $\begin{array}{l}\text { Bending Radius( } \mathrm{Rb}) \\
\text { at }-0.70 \%\end{array}$ & -53 to $-41 \mathrm{~dB}$ & -65 to $-59 \mathrm{~dB}$ & -79 to $-69 \mathrm{~dB}$ & -91 to $-82 \mathrm{~dB}$ & -110 to $-99 \mathrm{~dB}$ \\
\hline $\begin{array}{l}\text { Bending Radius( } \mathrm{Rb}) \\
\text { at }-1.40 \%\end{array}$ & 79 to $-69 \mathrm{~dB}$ & -91 to $-82 \mathrm{~dB}$ & -101 to $-93 \mathrm{~dB}$ & -119 to $-109 \mathrm{~dB}$ & -140 to $-130 \mathrm{~dB}$ \\
\hline $\begin{array}{l}\text { Wavelength }(\lambda) \text { at - } \\
0.70 \%\end{array}$ & -50 to $-41 \mathrm{~dB}$ & -63 to $-56 \mathrm{~dB}$ & -72 to $-63 \mathrm{~dB}$ & -95 to $-83 \mathrm{~dB}$ & -115 to $106 \mathrm{~dB}$ \\
\hline $\begin{array}{l}\text { Wavelength }(\lambda) \text { at - } \\
1.40 \%\end{array}$ & -75 to $-62 \mathrm{~dB}$ & -82 to $-79 \mathrm{~dB}$ & -97 to $-85 \mathrm{~dB}$ & -117 to $-106 \mathrm{~dB}$ & -138 to $-127 \mathrm{~dB}$ \\
\hline Trench width (Wt) & -14 to $-44 \mathrm{~dB}$ & -24 to $-50 \mathrm{~dB}$ & -35 to $-54 \mathrm{~dB}$ & -60 to $-80 \mathrm{~dB}$ & -85 to $-128 \mathrm{~dB}$ \\
\hline
\end{tabular}




\section{CONCLUSION}

The design of multicore fiber with trench assisted technique has been proposed. The simulation is done through MATLAB software. The simulation results exhibits the variation in crosstalk with respect to variation in bending-radius and wavelength for the trench width $4.5 \mu \mathrm{m}$ and $7 \mu \mathrm{m}$. The behavior of crosstalk is to be studied with variation in core pitch and trench width. And then the different core sizes are taken. The results exhibits the variation in crosstalk with respect to variation in bending-radius, wavelength and trench width. The ultralow crosstalk (less than $-100 \mathrm{~dB}$ per $100 \mathrm{~km}$ ) can be realized through the proposed core structures $\mathrm{C} 4$ and $\mathrm{C} 5$ mainly due to the suitable selection of $\Delta 1$ and core radius which can be used for short reach communication whereas the $\mathrm{C} 3$ core will be more suitable suitable long haul communication with less crosstalk. To analyze the relatively low crosstalk the trench assisted method has been showing better performance compared to other techniques such as depressed cladding and standard single mode fiber. And the fiber shows improved performance with trench width $7 \mu \mathrm{m}$ compared to previous study of trench width with $4.5 \mu \mathrm{m}$ and $6 \mu \mathrm{m}[2]$.The fiber can be used in the applications of long-distance communication, medical applications, etc.

\section{REFERENCES}

[1] Kunimasa Saitoh and Shoichiro Matsuo "Multicore fiber technology" - Osa publications 2018.

[2] Andres Macho Ortiz and Roberto Llorente Saez "multicore fiber: theory, application and opportunities" - intech open science and open mind - 2018

[3] Feihong Ye, Jiajing Tu, Kunimasa Saitoh, Katsuhiro Takenaga, Shoichiro, Hidehiko Takara, Toshio Morioka,” Design of Homogeneous Trench-Assisted Multi-Core Fibers Based on Analytical Model”- Journal of lightwave technology, 2016.

[4] Pramod R. Watekar, Seongmin Ju, and Won-Taek Han "Design and development of a trenched optical fiber with ultra-low bending loss"- OSA Optic express 2009.

[5] Dablu Kumar, Rakesh Ranjan "Crosstalk Suppression using Trench-assisted Technique in 9-core Homogeneous Multi Core Fiber" - 2017 IEEE.

[6] Dablu Kumar, Rakesh Ranjan "Analysis of Crosstalk Performance and its Reduction Amount in Single-mode Homogeneous Trench-assisted Multicore Fiber" - IEEE 2018 photonic letters.

[7] Tetsuya Hayashi " Multi-Core Optical Fibers Realizing High-Density/-Capacity Transmissions" -2016 IEEE.

[8] Adolfo V. T; Ruben S. Luís ; Benjamin J. Puttnam ; Tetsuya Hayashi ; Yoshinari Awaji ; Naoya Wada "Dispersion Impact on the Crosstalk Amplitude Response of Homogeneous Multi-Core Fibers" - IEEE 2016. 
[9] B. Jaramillo Ávila , J. M. Torres, R. de J. León-Montiel \& B. M. Rodríguez-Lara “Optimal crosstalk suppression in multicore fiber" - scientific reports 2019.

[10] F. Ye, J. Tu, K. Saitoh, K. Takenaga, S. Matsuo, H. Takara, and T.Morioka, Wavelength-Dependence of Inter Core Crosstalk in Homogeneous Multi-core Fibers, IEEE Photonics Technology Letters,January 2016.

[11] WeiWang, Shi Qiu, Haidong Xu, Tianxu Lin, Fanchao Meng, Ying Han, Yuefeng Qi,ChaoWang and Lantian Hou “Trench-Assisted Multicore Fiber with Single Supermode Transmission and Nearly Zero Flattened"- Dispersion- MDPI applied sciences-2018.

[12] Hui Yuan, Alessandro ottino, Yunno Xu, Arsalan Saljoghei, Tetsuya Hayashi, Tetsuya Nakanishi, Eric Sillekens, Lidia Galdino, Polina Bayvel, Zhixin Liu, and Georgios Zervas. ’Experimental Analysis on Variations and Accuracy of Crosstalk in Trench- Assisted Multi-core fibers” arXiv:200.08034v1[eess.p] electrical engineering and systems science- 2020.

[13] Sergi Garcia, Ivana Gasulla "Universal Characteristic equation for multi-layer optical fibers" IEEE journal of selected topics quantum electronics-2020.

[14] Dablu Kumar, Rakesh Ranjan “Optimal design of a single-mode trench-assisted homogeneous multicore fibre with a minimum crosstalk level”- Optical fibers' Quantum electronics-2019.

[15] C.T. Manimegalai, Sabitha Gauni, K. Kalimuthu, " Design and analysis of turbo-coded DCM-OFDM ultra-wideband system with radio-over-fiber and wireless transmission in underwater communication", Journal of Optics , vol. 49, pp 140146, March 2020.

[16] Gauni, S., Manimegalai, C.T., Krishnan, K.M., ...Arvind, V.V., Srinivas, T.V.N.,’Design and Analysis of Co-operative Acoustic and Optical Hybrid Communication for Underwater Communication", Wireless Personal Communications, 2021, $117(2)$, pp. 561-575 

Figures

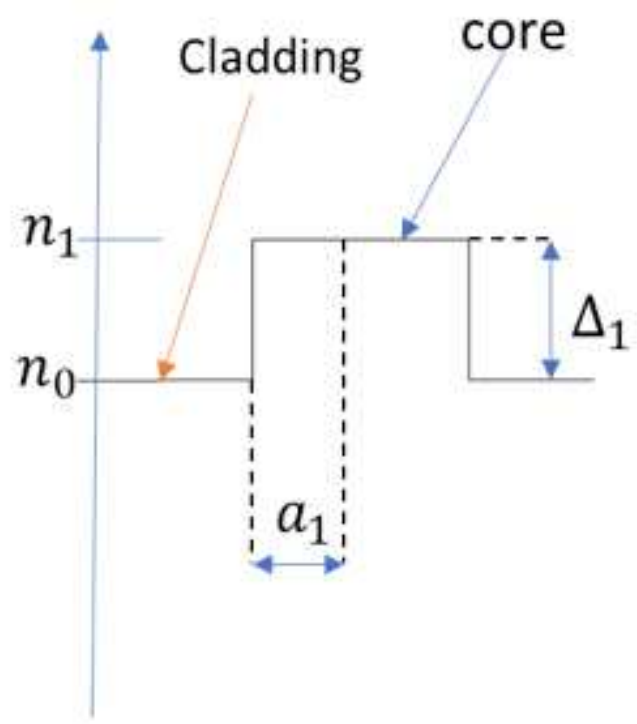

Figure 1

Step-index refractive index profile.

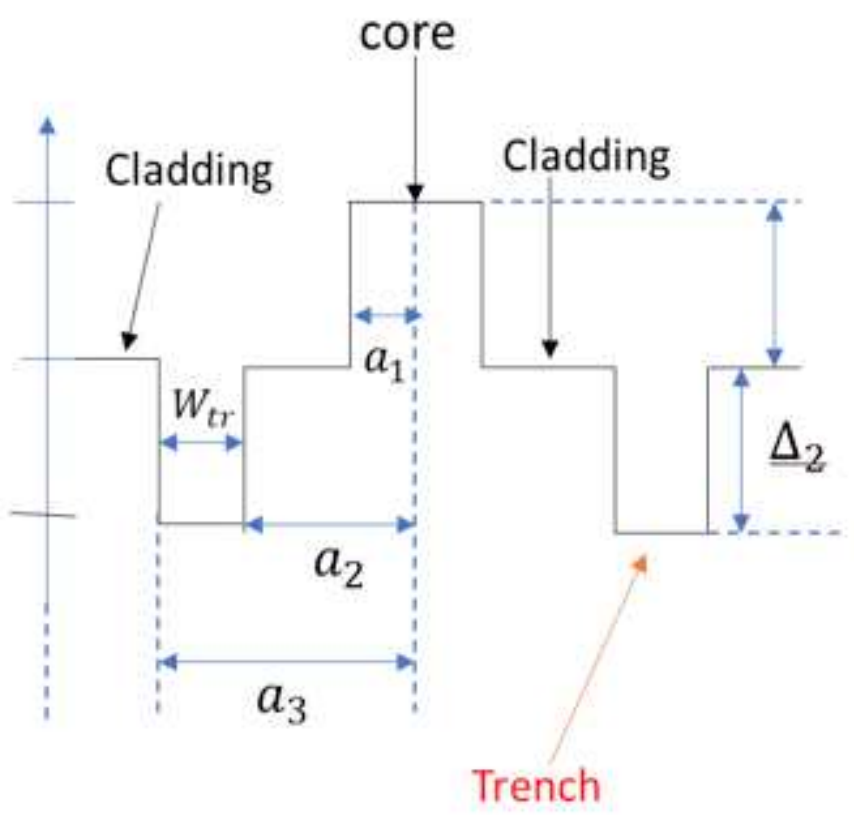

Figure 2

Trench assisted refractive index profile. 


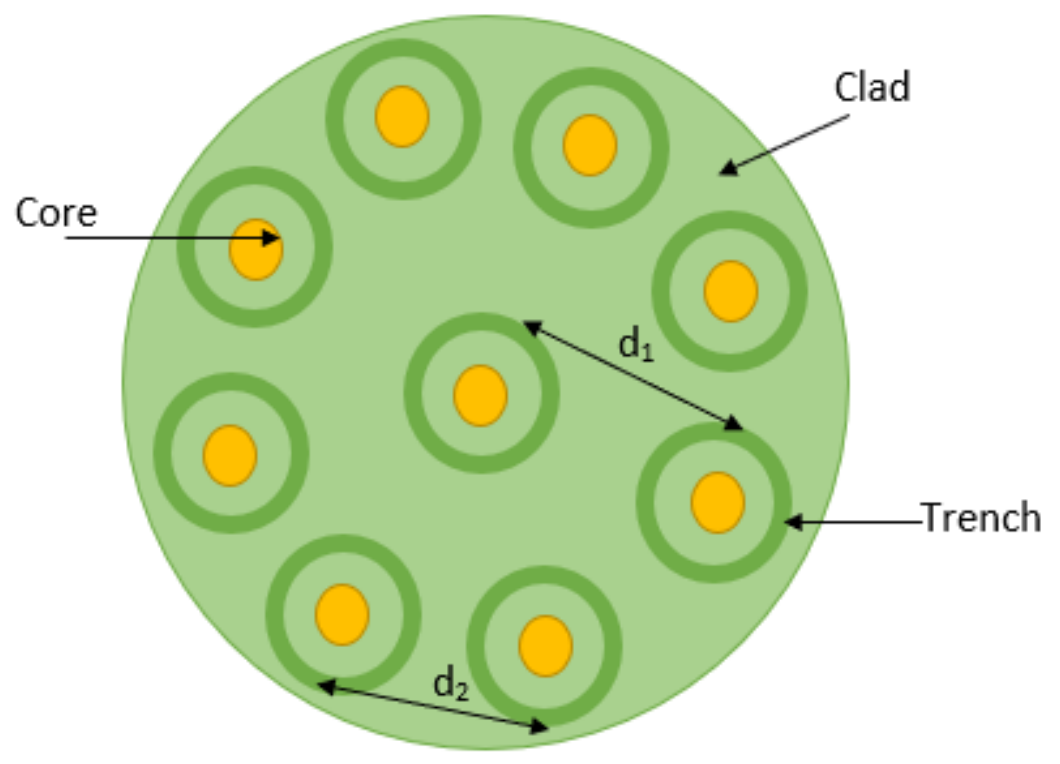

Figure 3

Cross-section view of MCF with 9-cores

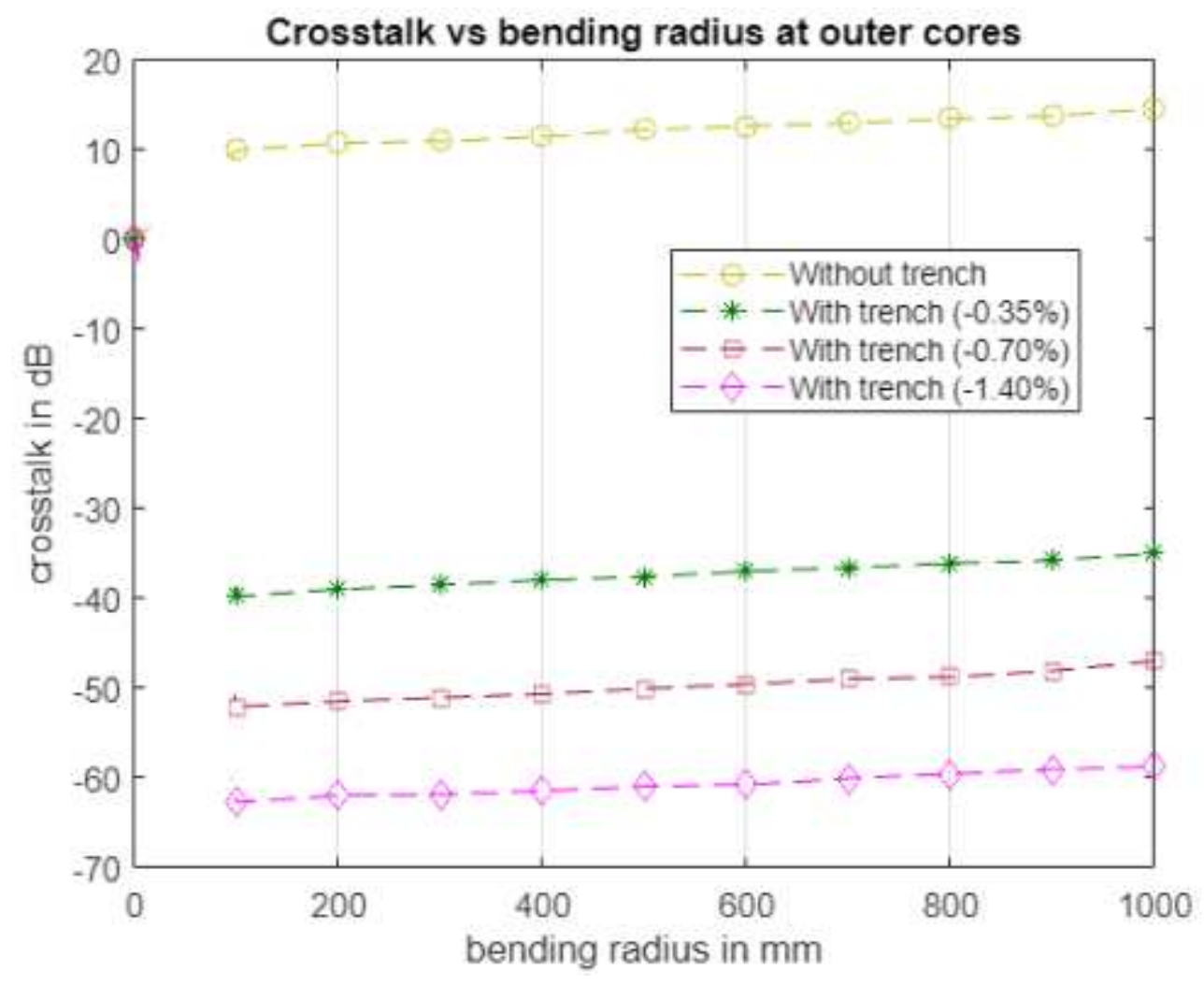

Figure 4

The relation between crosstalk and bending radius at outer cores. 


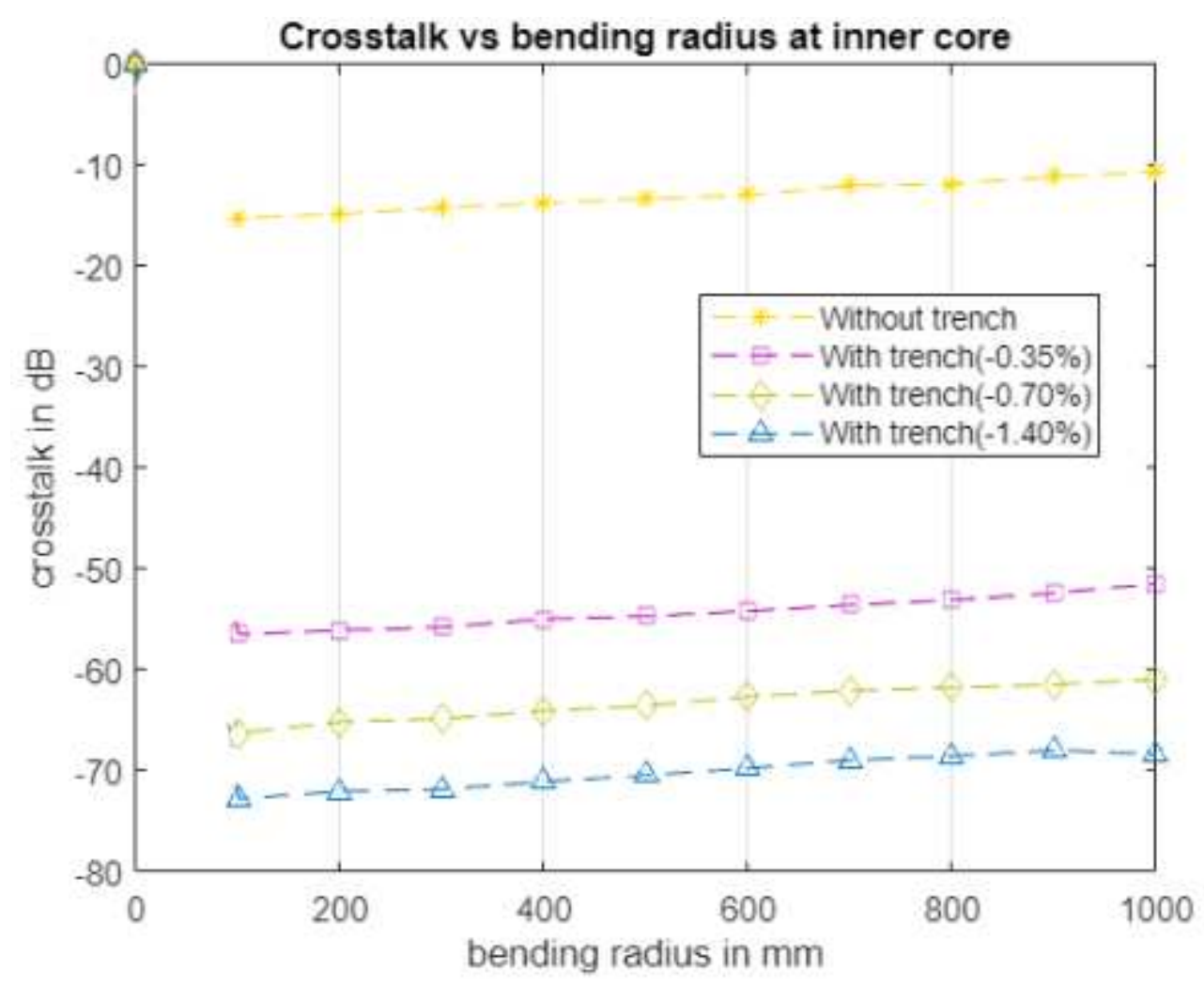

\section{Figure 5}

The relation between crosstalk and bending radius at inner core.

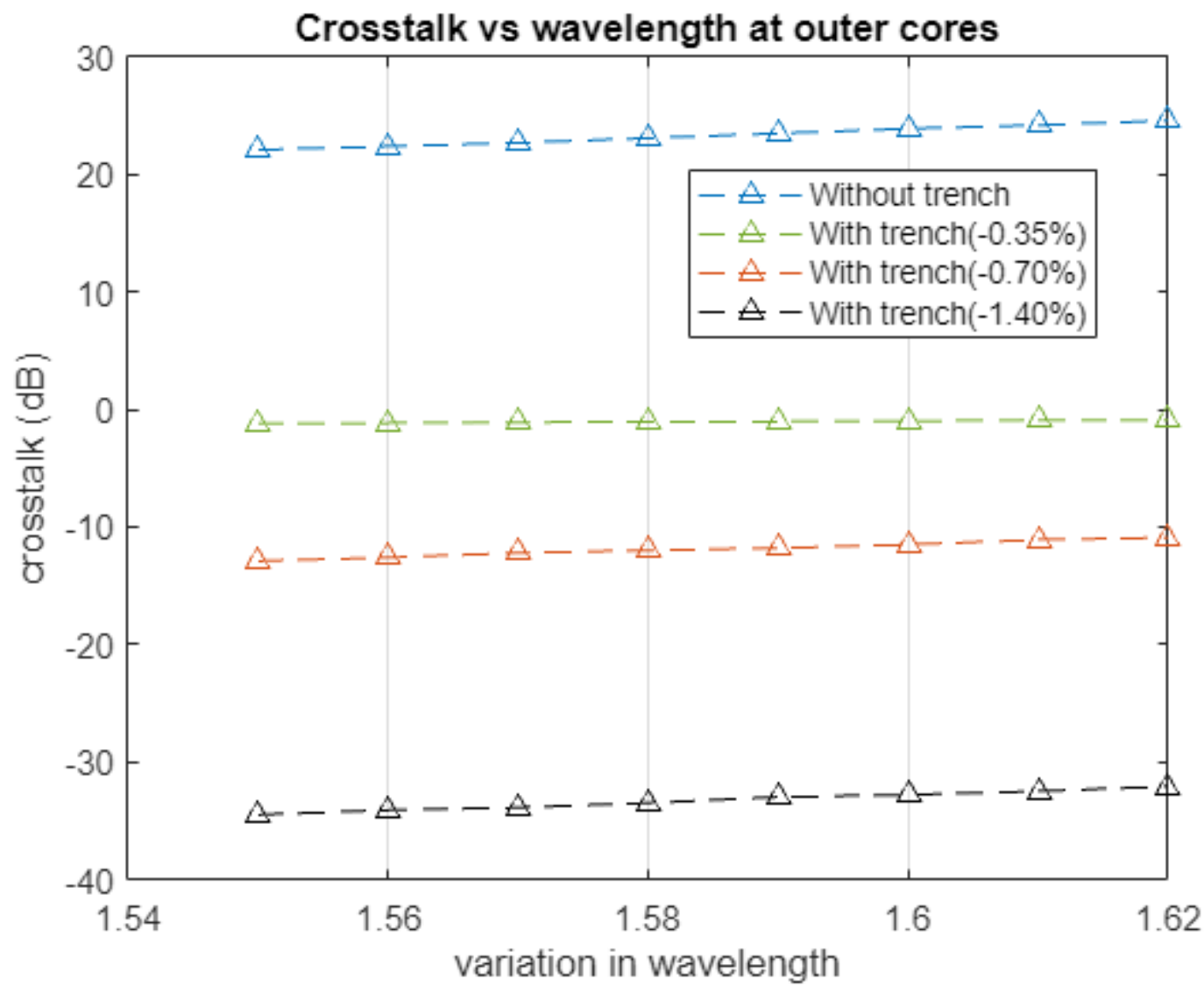

Figure 6 
The relation between wavelength in $\mu \mathrm{m}$ and crosstalk in cores at outer ring of the fiber.

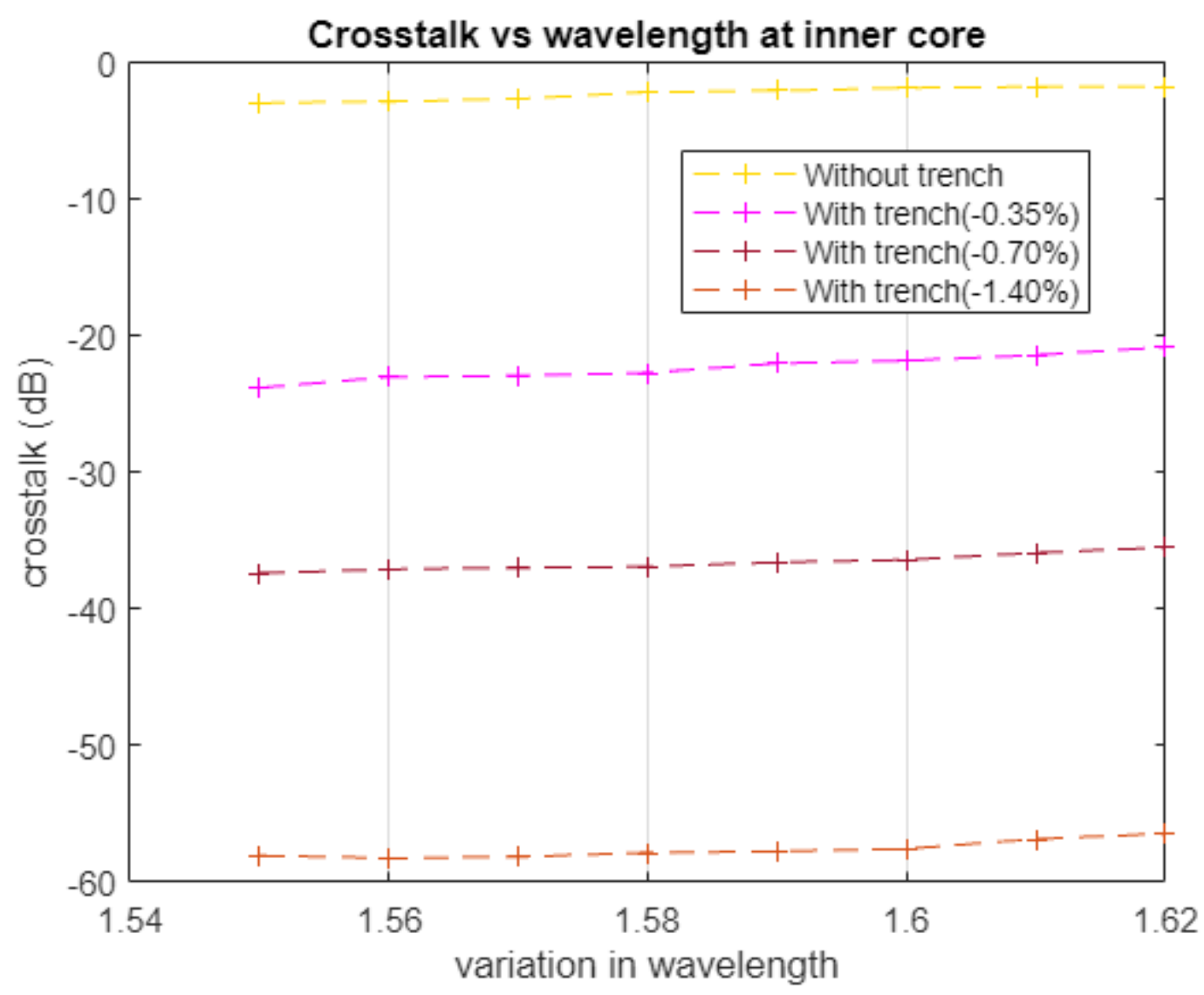

Figure 7

The relation between wavelength in $\mu \mathrm{m}$ and crosstalk at inner core, with core pitch. 


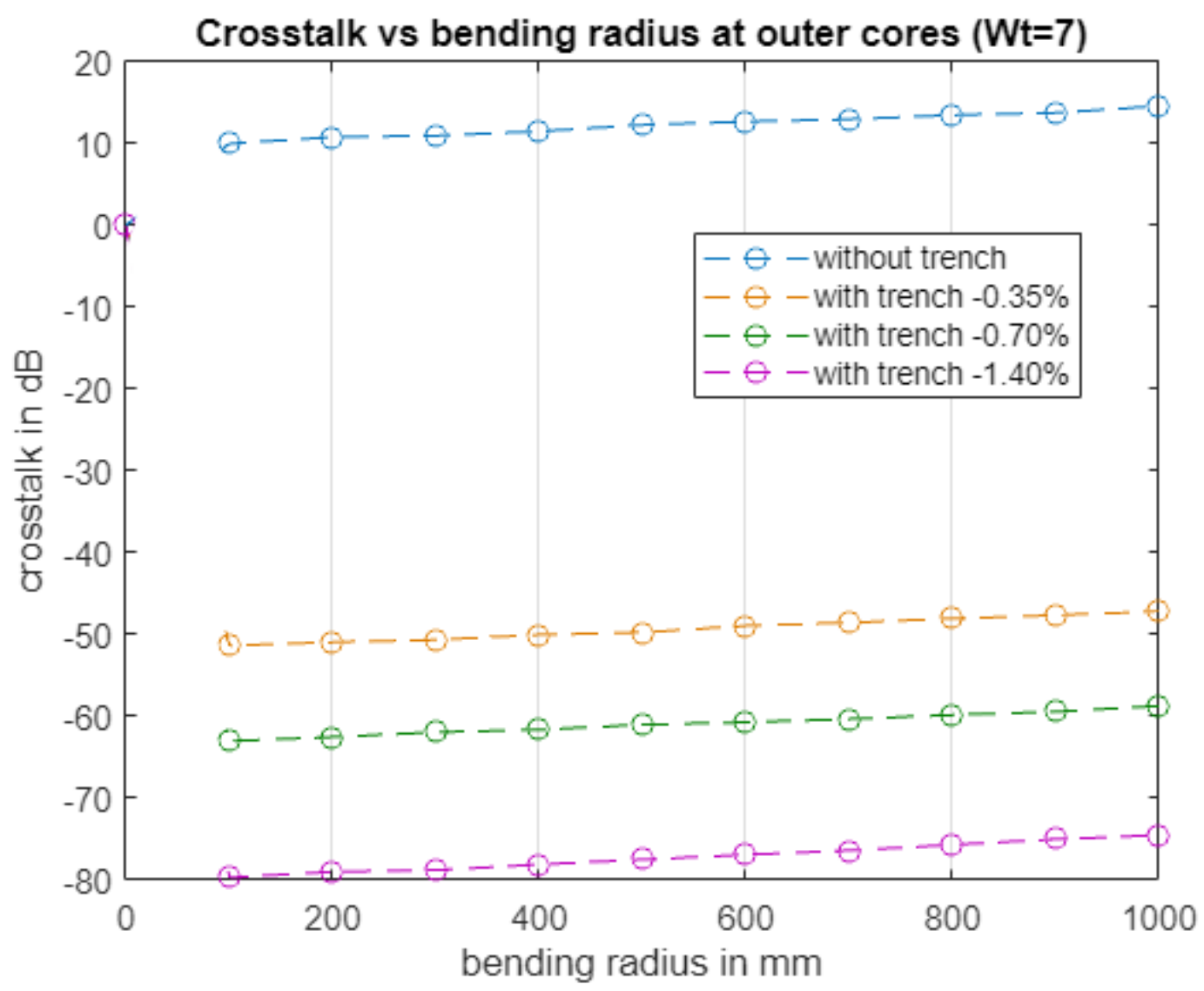

Figure 8

The relation between $\mathrm{XT}$ and bending radius at outer cores for $\mathrm{Wt}=7 \mu \mathrm{m}$. 


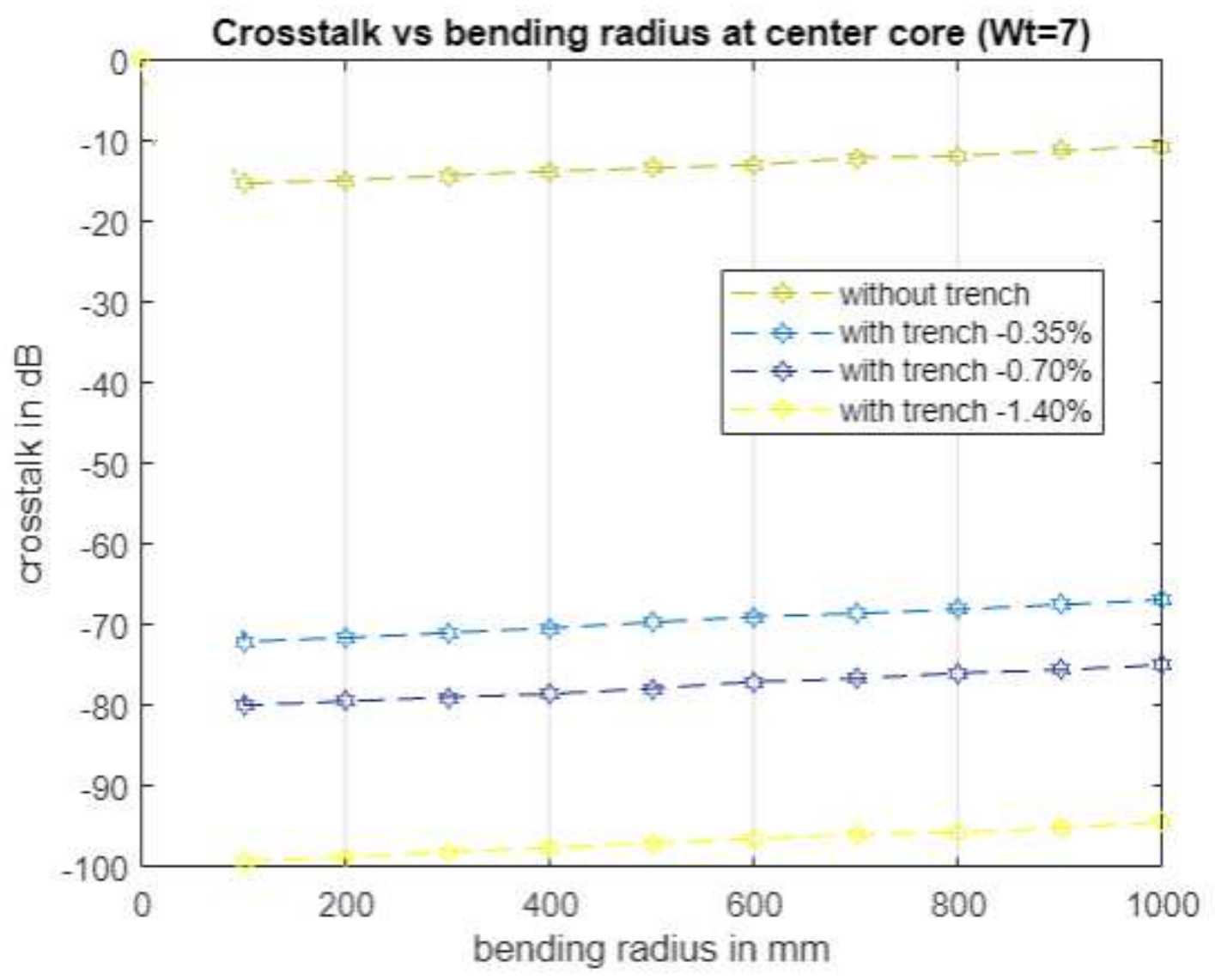

Figure 9

The relation between $\mathrm{XT}$ and bending radius at center core for $\mathrm{Wt}=7 \mu \mathrm{m}$.

Comparison of crosstalk variation with trench width $4.5 \& 7$ micrometer

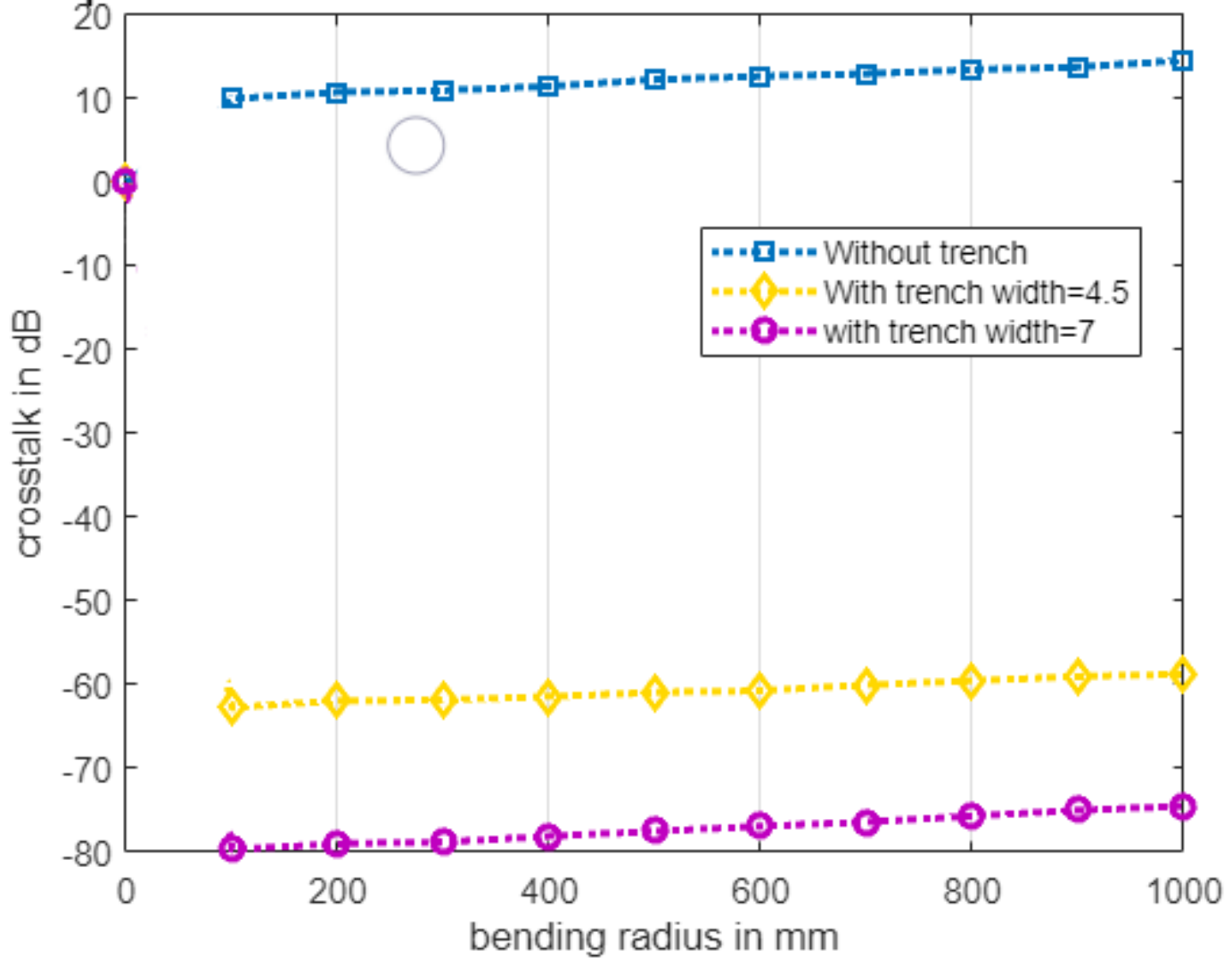


Figure 10

Shows the comparison of behavior of XT with variation in bending radius for $\mathrm{Wt}=4.5$ and $7 \mu \mathrm{m}$ at outer cores.

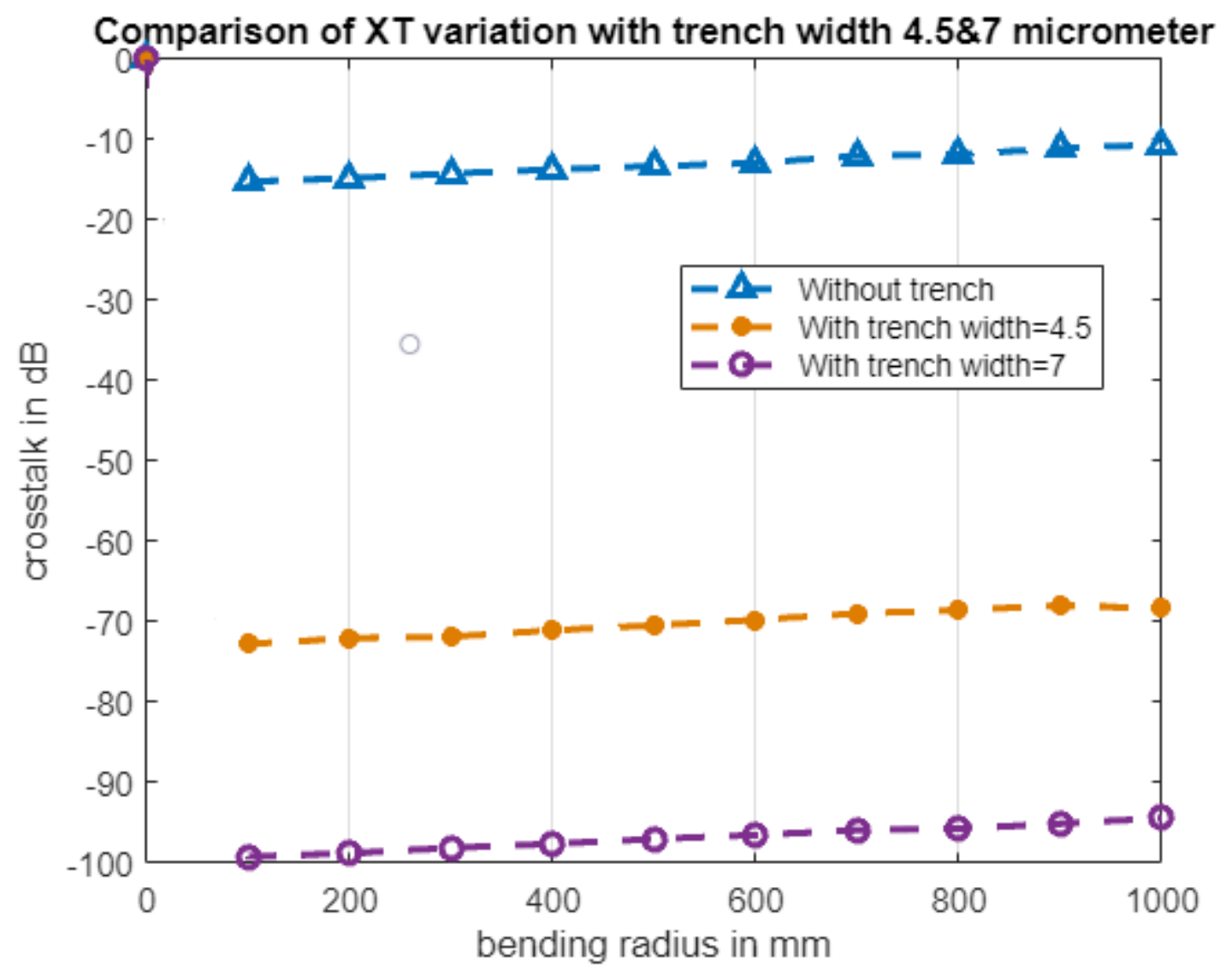

Figure 11

Shows the comparison of behavior of XT with variation in bending radius for $\mathrm{Wt}=4.5$ and $7 \mu \mathrm{m}$ at inner core. 


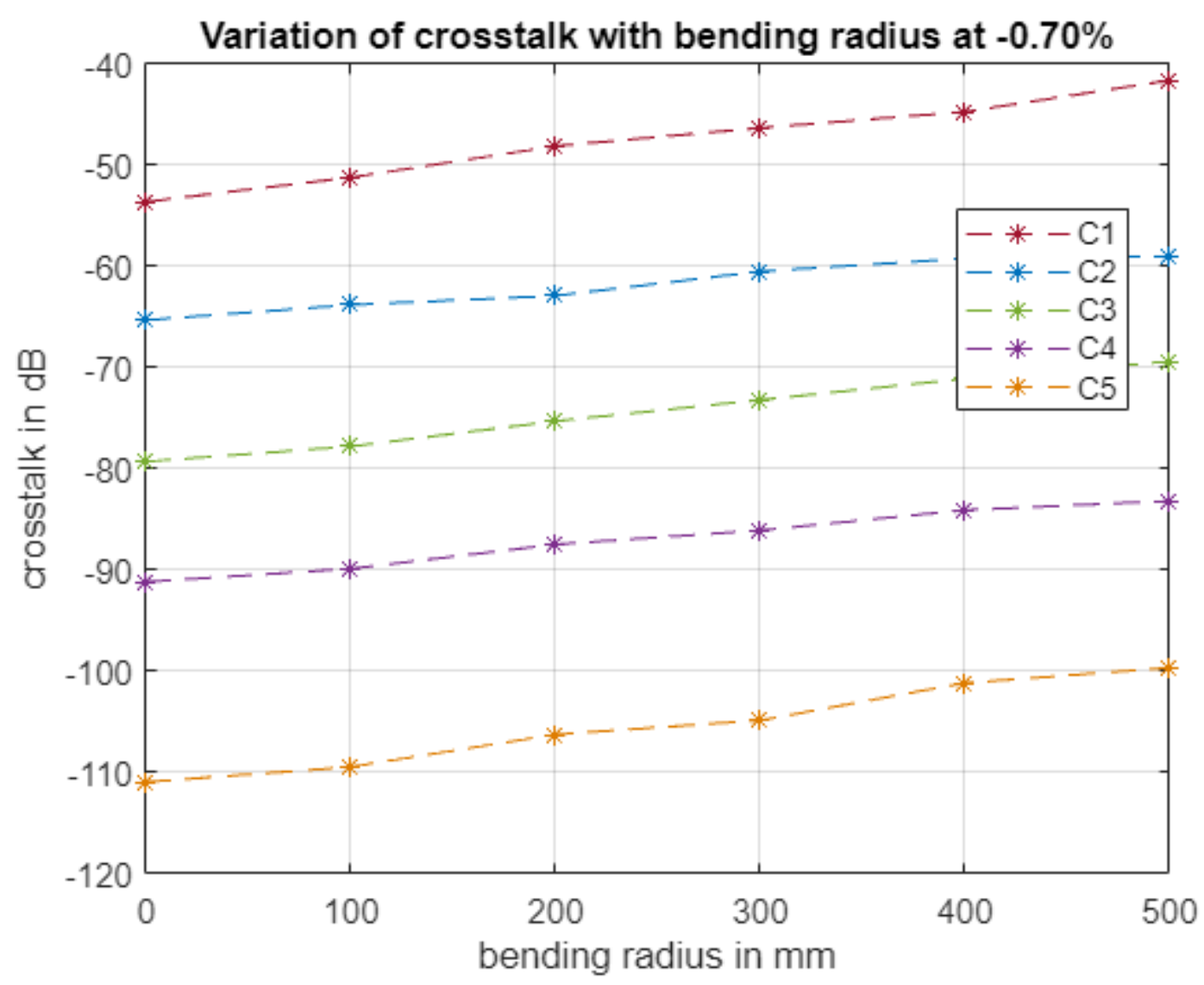

Figure 12

The crosstalk increases with increase in bending radius at trench depth $-0.70 \%$.

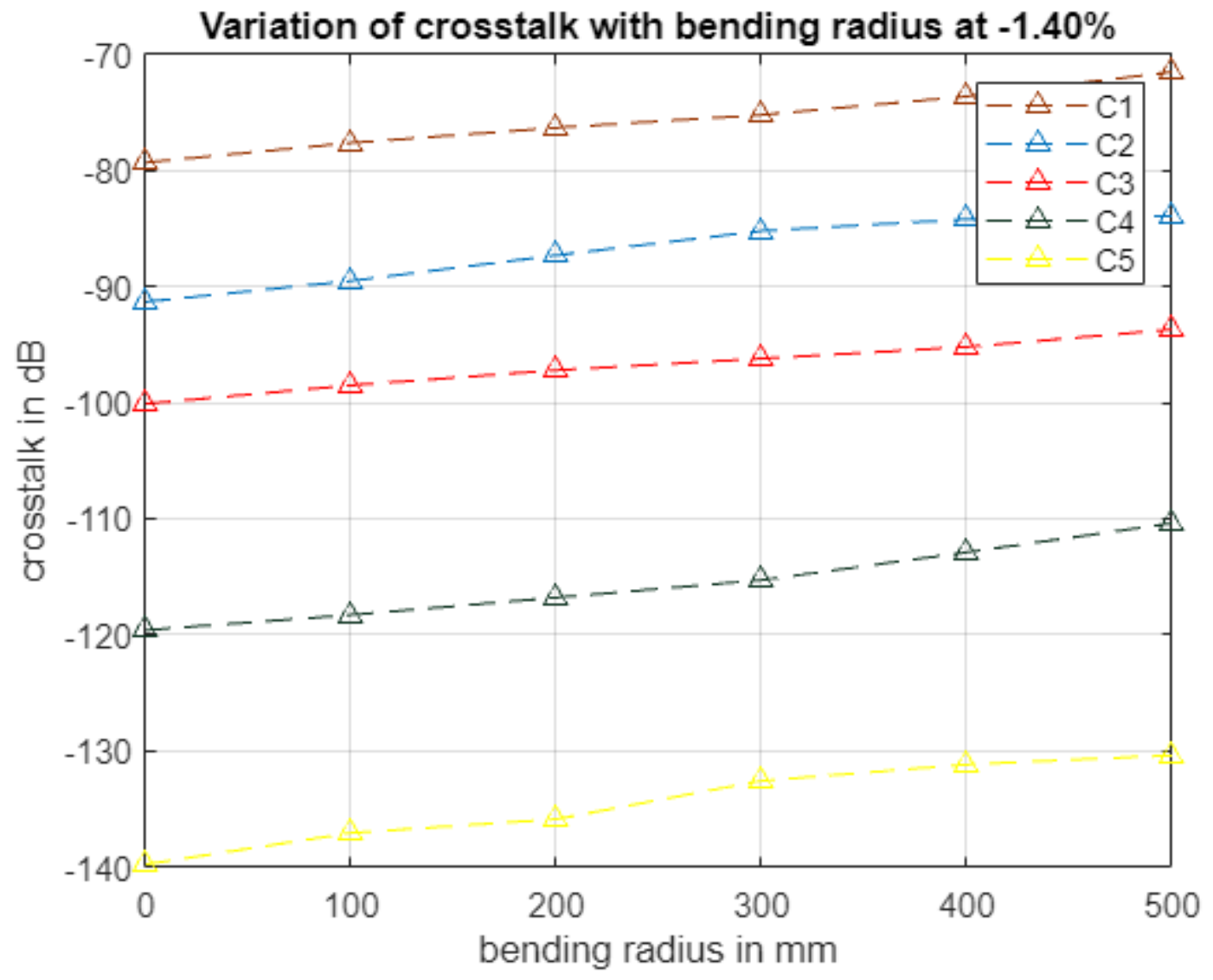


Figure 13

The crosstalk increases with increase in bending radius at trench depth $-1.40 \%$.

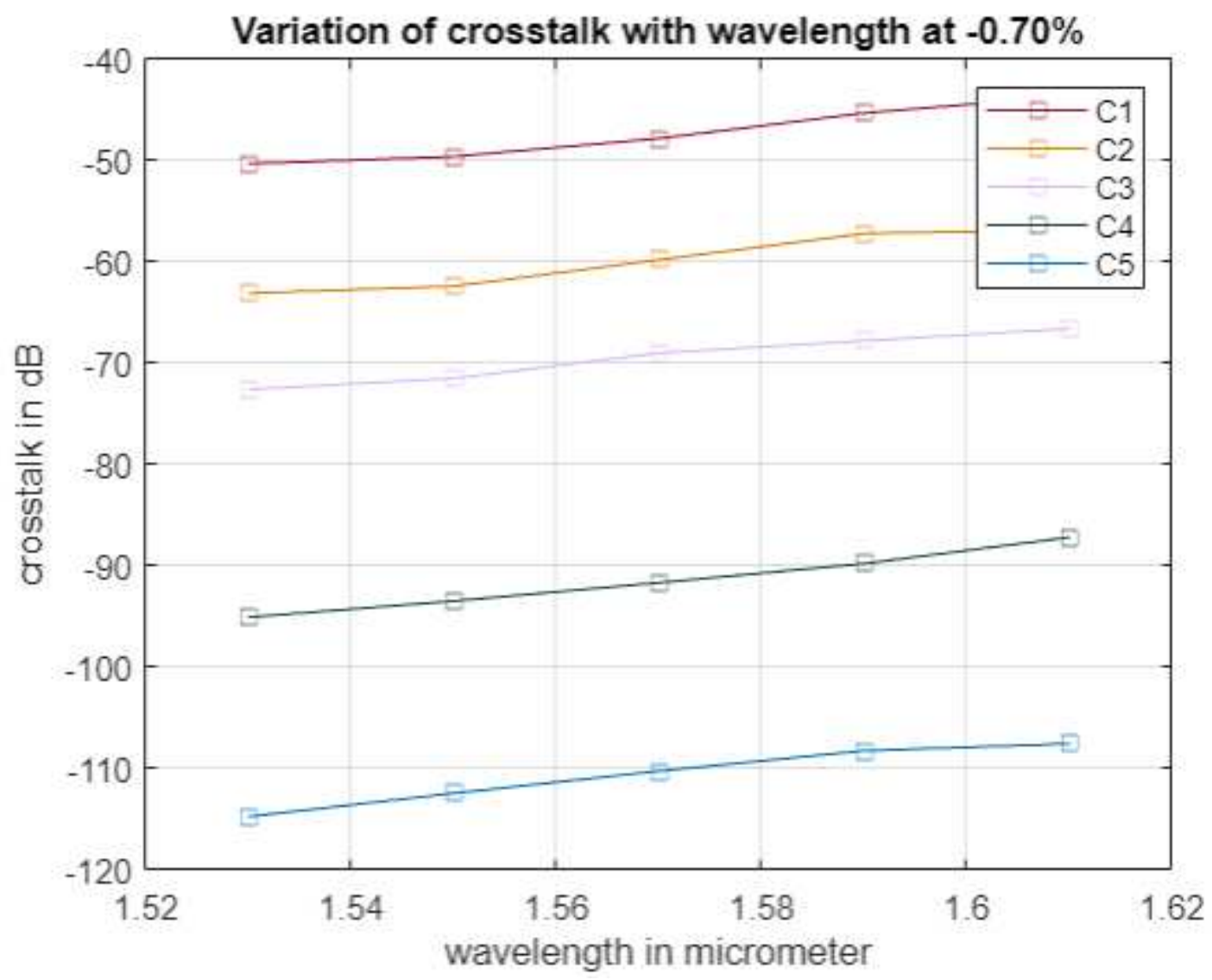

Figure 14

The crosstalk increases with increase in wavelength at trench depth $-0.70 \%$. 


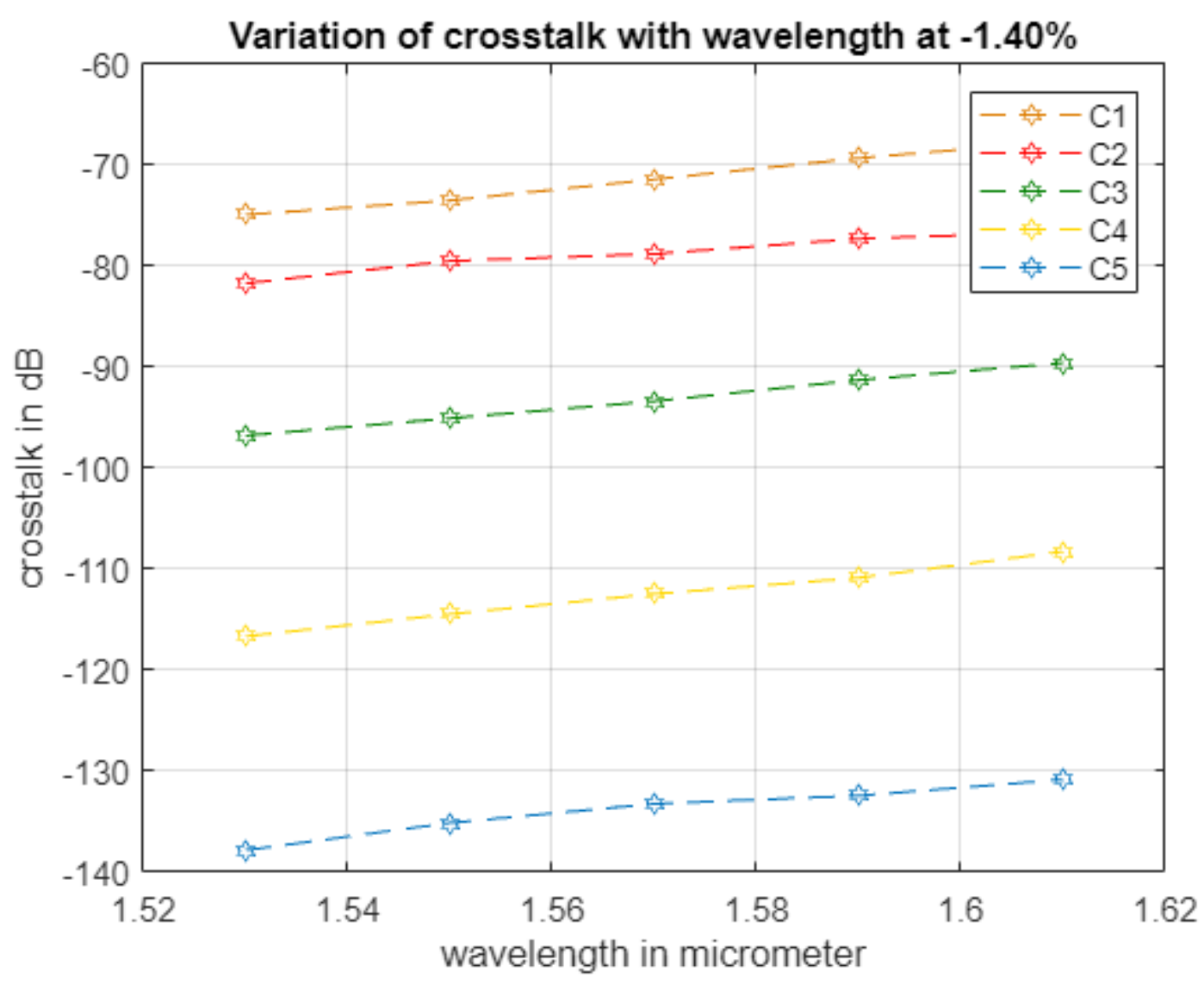

Figure 15

The crosstalk increases with increase in wavelength at trench depth $-1.40 \%$

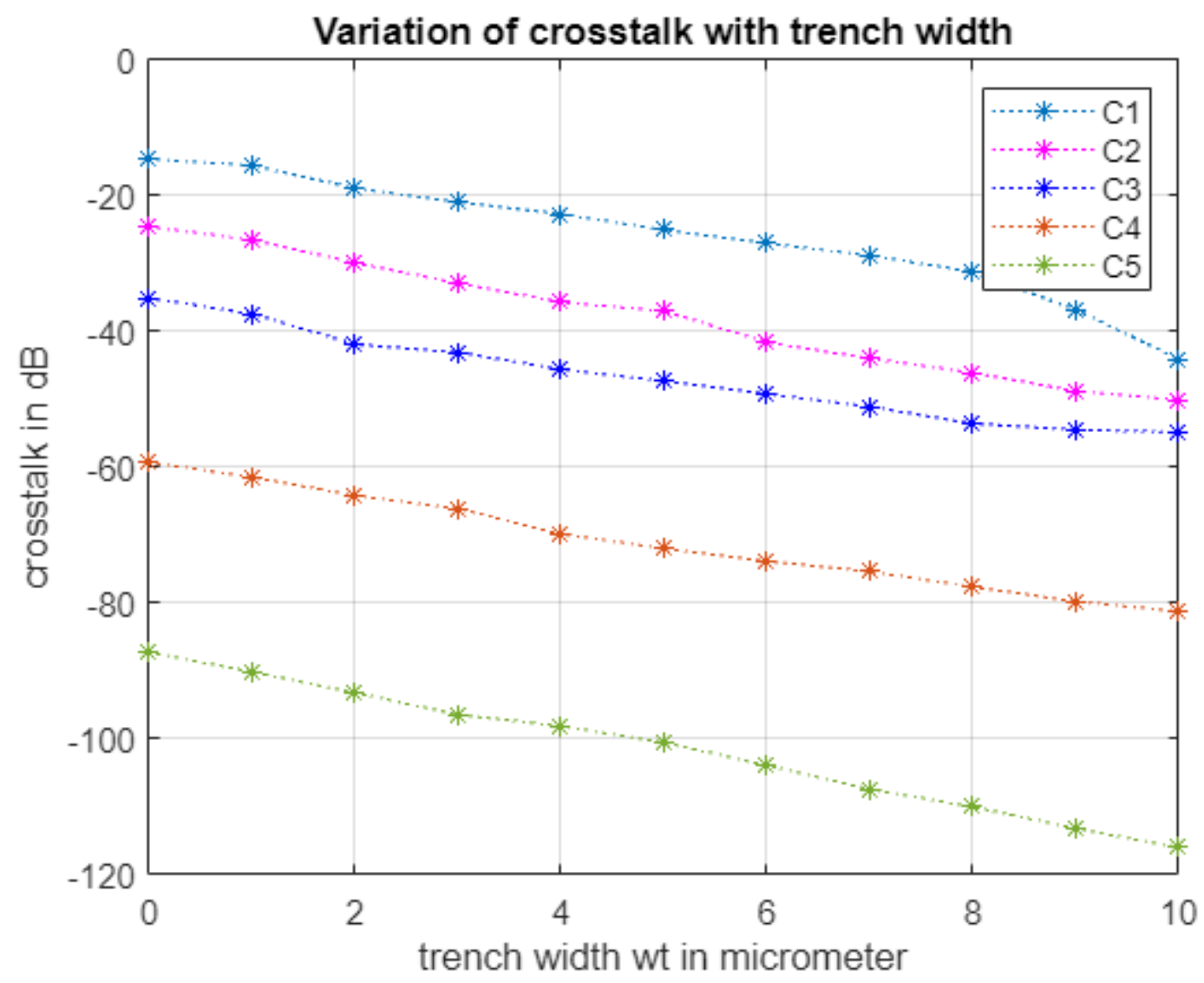


Figure 16

With the increase in trench width the crosstalk decreases 